\title{
Urbanização de baixo impacto (LID): Uso de geotecnologias para estimativa do tem- po de concentração de bacia em cenário de pré-desenvolvimento.
}

\section{Low Impact Urbanization (LID): Use of geotechnologies to estimate the concentration time of a basin in a pre-development scenario}

\author{
Nelson R. Amanthea ${ }^{1}$ e Nilo de Oliveira Nascimento ${ }^{2}$
}

\author{
${ }^{1}$ Programa de Pós Graduação em Saneamento Meio Ambiente e Recursos Hídricos - SMARH/UFMG \\ Universidade Estadual de Londrina (UEL), Pró-Reitoria de Planejamento (PROPLAN), \\ Diretoria de Planejamento e Desenvolvimento Físico (DPDF),
}

amanthea@uel.br

\begin{abstract}
${ }^{2}$ Programa de Pós Graduação em Saneamento Meio Ambiente e Recursos Hídricos - SMARH/UFMG, Universidade Federal de Minas Gerais (UFMG), Departamento de Engenharia de Recursos Hídricos - EHR, Universidade Federal de Minas Gerais, niloon@ehr.ufmg.br.
\end{abstract}

Recebido: 24/01/14 - Revisado: 01/04/14 - Aceito: 27/08/14

\section{RESUMO:}

As técnicas de baixo impacto de urbanização, ao estabelecerem entre seus princípios norteadores a manutenção do tempo de concentração (TC) da situação de pré-desenvolvimento, implicitamentetransformam-no em um importante indicador para o desenvolvimento de projetos e planejamento físico-territorial urbano. Entretanto, diante da multiplicidade de definições e métodos para se estimar o valor do TC de uma determinada bacia hidrográfica, ressurge uma questão para a qual a literatura técnica ainda busca a resposta adequada: qual seria o método mais apropriado a esse propósito, que pudesse ser recomendado aos órgãos de planejamento nas suas realidades locais? Este trabalho, utilizando-se de uma bacia rural monitorada, em suposto cenário de pré-desenvolvimento urbano, faz. uma reflexão sobre o tema e aponta o uso de método de velocidade modificado, associado à geotecnologia, como alternativa recomendável para estimativado TC. Além de oferecer maior confiabilidade de valor, a espacialização do TC possibilita clara compreensão de sua ocorrência a partir de cada ponto da bacia. Dessa forma, torna-se viável ainda a adoção,pelo projetista,de critérios de verificação de consistência na escolha de pontos mais representativospara a definição do valor final do TC, em contraposição a sistemas de cálculo que oferecem opcões de valores isolados, obtidos por diferentes métodos empíricos sem haver qualquer referência de um "valor verdade". A espacialização do TC possibilita ainda o planejamento de pesquisa de medição direta para a determinação do TC e de eventos na bacia que dependam do tempo de translado do escoamento superficial, a exemplo de sistemas de alerta contra inundacoões ou transporte de poluentes.

Palavras Chave: LID. Tempo de concentração. Geoprocessamento. Bacia hidrográfica. Planejamento urbano.

\begin{abstract}
The Low Impact Development (LIC) techniques, when establishing among their guiding principles the maintenance of time of concentration (TC) of the predevelopment site, implicitly transform TC into one of the most important indicators for project development and urban physical-territorial planning. However, due to the multiplicity of definitions and methods for estimating the value of TC of a particular river basin, an issue reappears for which the technical literature is still seeking the right answer: which is the most appropriate method to be recommended for this purpose to planning agencies in dealing with their local realities? This work, using a rural watershed in a supposed scenario of urban predevelopment, reflects on the topics and points at the use of a modified velocity method associated with geotechnology as a good alternative to estimate the TC. Besides offering a more reliable estimate of value, the spatialization of TC enables better understanding of its occurrence from every point in the basin. Thus, it is still feasible to adopt criteria for validation by the engineer in selecting the most representative point of the TC as opposed to systems of calculation that offer options of simple values obtained from empirical methods without having any reference to a "true value". The spatial distribution of the TC also enables research planning of direct measurement for the determination of TC and planning of events in the basin that depend on the travel time of flow such as flood warning systems or transport of pollutants.
\end{abstract}

Keywords: LID. Time of concentration. Geoprocessing. Watershed. Urban planning. 


\section{INTRODUÇÃO}

A urbanização de baixo impacto - LID (Low Impact Development) tem sido difundida como estratégia de gerenciamento de águas pluviais para manter a hidrologia local e mitigar impactos adversos ao escoamento superficial e à poluição difusa. Em sistemas de LID, o tempo de concentração (TC) passa a ser OBSERVADO também como parâmetro indicador da situação de pré-desenvolvimento urbano que não pode ter seu valor reduzido na urbanização (DER, 1999; DOD, 2010).

Este artigo faz parte de um projeto que irá investigar os benefícios de LID em uma bacia monitorada, onde o TC será um dos parâmetros utilizados na análise de seu comportamento hidrológico.

A Bacia do córrego do Mato Frio (BMF), escolhida para o desenvolvimento do projeto, dispõe de registros hidrológicos de doze anos de monitoramento contínuo de vazões, em intervalos de 10 minutos, realizado pelo Centro de Desenvolvimento da Tecnologia Nuclear (CDTN), além de contar com informações do Serviço Geológico do Brasil - CPRM (Companhia de Pesquisa de Recursos Minerais), operador desta bacia desde agosto de 1976. Localiza-se no município de Itaúna, contíguo à região metropolitana $(\mathrm{RMBH})$ e distante cerca de $50 \mathrm{~km}$ de Belo Horizonte (Figura 1). Trata-se de uma bacia rural com área de $11 \mathrm{~km}^{2}$ e relevo entre ondulado ( 8 a 20\% em 40,8\% da área) a forte ondulado (20 a 45\% em 46,5\% da área). O córrego do Mato Frio é um dos formadores do ribeirão Serra Azul, que juntamente com o Mateus Leme formam o rio Juatuba, afluente do Paraopeba, da sub-bacia 40 (Alto São Francisco). O Serra Azul e o Mateus Leme são os principais cursos d'água que compõem a Bacia do Juatuba, representativa da região central de Minas Gerais. As características do relevo da BMF não são incomuns na região metropolitana e por isto a bacia está sendo estudada também em simulações de urbanização por sua similaridade com outras, densamente ocupadas na RMBH.
Diante da perspectiva de se utilizar o TC como referência para o planejamento urbano emergem duas questões: qual o conceito de tempo de concentração a ser utilizado e qual método poderia ser recomendado aos órgãos de planejamento para estimativa do valor de TC como indicador na recuperação de áreas ou planejamento de novos empreendimentos urbanos?

\section{Conceitos de TC}

O tempo de concentração é uma grandeza fundamental para análises hidrológicas e compreensão do escoamento produzido em uma bacia hidrográfica (FANG et al., 2008; MATA -LIMA et al., 2007). Sua magnitude influencia o pico e a forma do hidrograma de escoamento (GUPTA, 2011; MATA-LIMA et al., 2007; TUCCI, 2001). Trata-se da variável de tempo mais conhecida e utilizada pelos engenheiros que atuam nas áreas de hidrologia e hidráulica e uma das mais importantes entradas de projetos hidrológicos de bacias hidrográficas (KANG et al., 2008; MCCUEN et al. 1984; MCCUEN, 2009; WONG, 2009). Sua importância destaca-se ainda pela utilização crescente em grande variedade de modelos hidrológicos modernos (ALVAREZ, 2006; GRIMALDI et al., 2012).

As técnicas de LID focalizam o comportamento hidrológico da bacia como um todo e não apenas as cheias. Tanto a urbanização quanto as detenções concentradas ou distribuídas no espaço físico urbano alteram as características do escoamento superficial (HAWLEY et al., 1981; MCCUEN, 1998). Chuvas críticas de duração maior do que o tempo de concentração podem produzir vazões maiores do que as previstas para o TC, principalmente quando há armazenamento na bacia, como demonstra o trabalho de DINIZ (2002). Ainda assim, o TCé tido como tempo crítico, a exemplo das técnicas baseadas no conceito de Hidrograma Unitário (HU) e HU sintéticos paramétricos (Alvarez, 2006; Green; Nelson, 2002; Wilken, 1978); na determinação da intensidade de precipitação de curvas IDF,

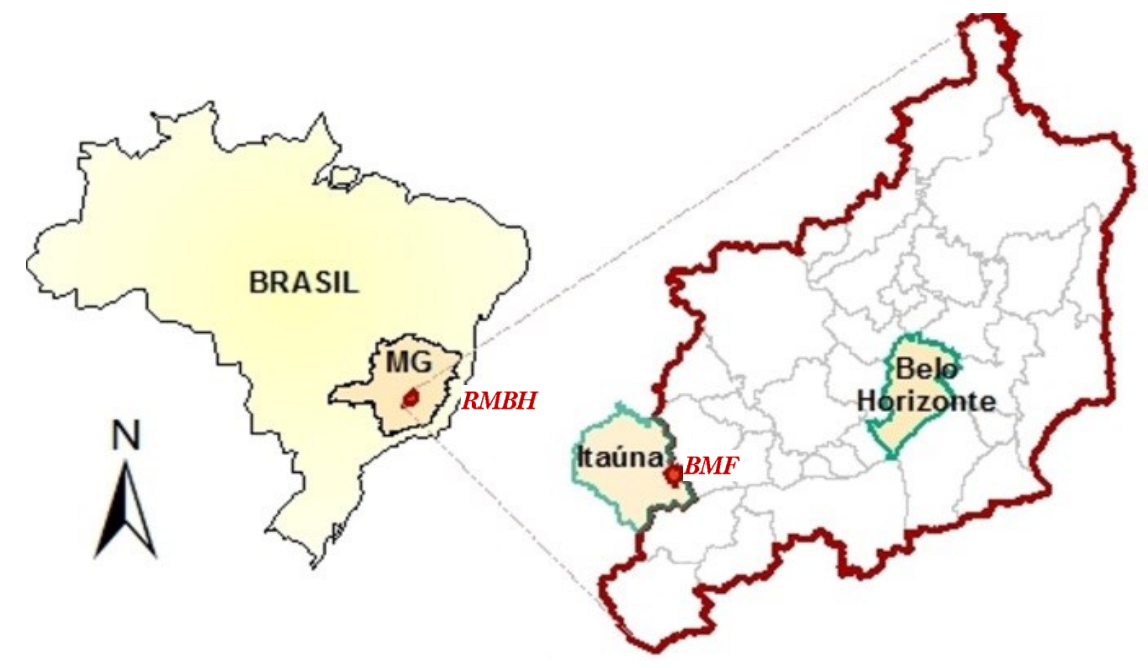

Figura 1 - Bacia do Mato Frio (BMF): situação 
Falaguasta e Genovez, (2003) na previsão de vazão Silva et al., (2006), na determinação da vazão de pico para o dimensionamento de estruturas hidráulicas Fang et al., (2007), Kang et al. (2008), Sharifi e Hosseini, (2011) e no dimensionamento de sistemas de drenagem, armazenamento e controle (MATA-LIMA et al., 2007).

Apesar da importância do TC para a hidrologia, Singh (1988) já alertava sobre suas diversas definições e Grimaldi et al. (2012), Sharifi e Hosseini (2011), ainda atualmente, esclarecem que não há um único conceito que possa ser considerado universal para se contrapor à multiplicidade de definições que permeiam a literatura técnica. Outros autores como Akan (1986), Guo e Adams (1998) afirmam que o TC é definido vagamente na literatura.

Na tentativa de sistematização, Grimaldi et al.(2012) baseados em McCuen et al. (1984), relacionam seis definições "computacionais" vinculadas a informações sobre chuva e escoamento superficial e duas "teóricas", respectivamente correspondentes à do ponto hidraulicamente mais distante da saída da bacia em estudo e a que considera o tempo desde o fim da chuva efetiva até o fim do escoamento superficial.

Maidment (1993) defende que o TC é um conceito idealizado que reflete a resposta de uma bacia para determinado evento de chuva.

A definição de TC como o tempo necessário para que toda a bacia contribua na seção de saída pressupõe a mesma como reservatório para o escoamento superficial direto, geralmente representado por uma combinação de efeitos de translação e armazenamento. Segundo Silveira (2005), o efeito de translação pode ser considerado linear, mas o de armazenamento não, já que varia com a carga hidráulica e implica diminuição do TC com o aumento de intensidade da chuva. Através do modelo conceitual representado pela Figura 2, uma bacia inteira pode ter o processo de transferência de fluxo de água em seu interior definido por um único operador, que conduz a resposta biofísica da bacia (uso e ocupação, vegetação, características geomorfo- lógicas, pedológicas, geológicas e biológicas) à sua saída.

Nesta hipótese, o TC seria o tempo de equilíbrio quando o regime permanente fosse estabelecido entre uma chuva efetiva de intensidade constante e o seu escoamento superficial direto (CHOW et al., 1988; MAIDMENT, 1993; SILVEIRA, 2005).

Estão implícitas ainda nesse conceito idealizado de TC as hipóteses de que a evapotranspiração seja desprezível, que o solo esteja saturado por chuva antecedente e que a precipitação seja uniformemente distribuída na bacia e constante no tempo.

Admite-se, também, o TC com oscilação tão pequena de valor que pode ser considerada invariável em relação à intensidade de precipitação, conforme mostram estudos realizados por Dooge (1973), Drumond (2004) e Grimaldi et al. (2012) durante a ocorrência de eventos de cheia com alto periodo de retorno. Para Silveira (2005), ao se admitirem a propagação de onda e um valor de referência constante para a intensidade da chuva, o TC pode ser considerado como parâmetro hidrológico invariável. Com base nessas hipóteses, a definição mais comumente empregada, considera, de forma implícita, que o tempo de concentração refere-se a um valor constante que determina o quanto o escoamento leva para atingir a saída da bacia em estudo, a partir do ponto hidraulicamente mais distante (USDA, 1986).

\section{Métodos para Estimativa de TC}

Diante da pluralidade de definições com simultaneidade de uso, estabelecer um único e confiável método de estimativa para o TC torna-se um desafio. A falta de efetividade de medições diretas de TC contribui para esse quadro de múltiplos caminhos de escolha e sem referencial único. Ben-Zvi e Sheva (2013) chegam ao ponto de afirmar que a variável TC é imensurável. Talvez esse posicionamento mais radical tenha relação com as dificuldades de se realizarem medições práticas e precisas que considerem integralmente as várias definições e todos os seus pressupostos.

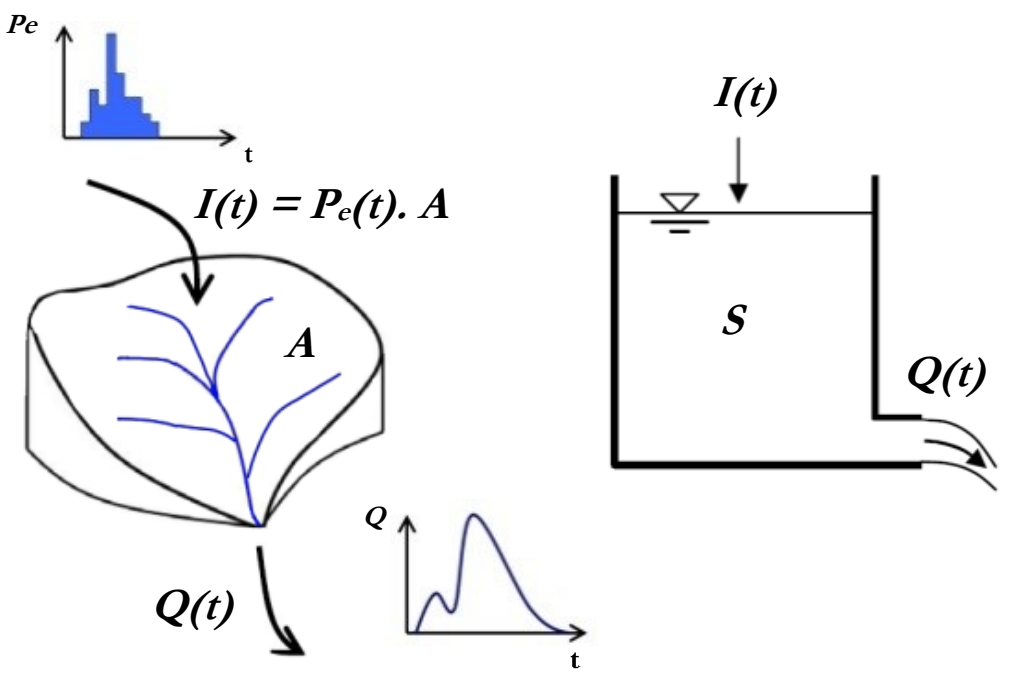

Figura 2 - Bacia hidrográfica esquematizada como um sistema (Reservatório S) Fonte: Adaptado de Todini e Martina (2008) e Versace (2004) 


\section{Medição Direta de TC}

Entre as raras pesquisas para medição direta pode-se citar os exemplos do australiano Pilgrim (1976) e do brasileiro Drumond (2004), que empregaram traçadores em suas medições. A medição direta de Drumond (2004), através de traçador fluorescente (predominantemente, Rodamina WT a 20\%), foi realizada na BMF e compreendeu 19 campanhas durante um período de cinco anos, sendo a primeira de testes e duas sem resultados. A partir de um dos pontos escolhidos lançava-se certa quantidade de traçador e monitorava-se a passagem da frente de avanço do mesmo no exutório da BMF. A Tabela 1 e a Figura 3 sumarizam os resultados experimentais obtidos por DRUMOND (2004).

Drumond (2004)relata que as incertezas nos resultados (valor médio 13,3\%) foram atribuídas principalmente ao tempo de coleta de amostras em intervalos de uma hora. Apesar de facilitar as operações de campo, o intervalo de coleta adotado era próximo do valor de TC esperado para a BMF, o que implicou uma incerteza máxima nos resultados estipulada em meia hora.

O erro absoluto médio (ē) foi estimado através dos $n$ valores observados $\left(T C_{o b s}\right)$ e calculados a partir da curva ajustada $\left(T C_{\text {call }}\right)$

Tabela 1 - BMF: Medição Direta do Tempo de Concentração

\begin{tabular}{|c|c|c|c|c|c|c|c|c|c|c|c|}
\hline \multirow[t]{3}{*}{ Evento } & \multirow[t]{3}{*}{ Campanha } & \multirow[t]{3}{*}{ Data } & \multirow[t]{3}{*}{$\begin{array}{c}\text { Ponto } \\
\text { de } \\
\text { Lançamento }\end{array}$} & \multirow{3}{*}{$\begin{array}{c}\text { Precipitação } \\
(\mathrm{mm})\end{array}$} & \multirow{3}{*}{$\begin{array}{c}\text { Duração } \\
\text { (b) }\end{array}$} & \multirow{3}{*}{$\begin{array}{c}\text { Intensidade } \\
\text { de } \\
\text { Precipitação } \\
(m m / b)\end{array}$} & \multirow{3}{*}{$\begin{array}{c}\text { Vazão na } \\
\text { passagem da } \\
\text { frente de avanço } \\
\text { do traçador } \\
0 \\
(l / s)\end{array}$} & \multicolumn{3}{|c|}{$\begin{array}{c}\text { Tempo de Concentração } \\
T C=37,5 \cdot Q^{-0,3275}\end{array}$} & \multirow{3}{*}{$\begin{array}{l}\text { Incerteza } \\
0,5 \mathrm{~h} / \mathrm{TC}_{\text {ob }}\end{array}$} \\
\hline & & & & & & & & \multicolumn{2}{|c|}{ Observado $\left(T C_{\text {oks }}\right)$} & \multirow{2}{*}{$\begin{array}{c}\text { Calculado }\left(T C_{\text {cak }}\right) \\
(\text { b) }\end{array}$} & \\
\hline & & & & & & & & (b:min) & (b) & & \\
\hline 0 & 1 & $24 /$ out $/ 97$ & T3 & 0,0 & 0,0 & 0,0 & 148,0 & $09: 30$ & 9,500 & 7,299 & $5,3 \%$ \\
\hline 1 & 2 & $24 / \operatorname{dez} / 97$ & T3 & 14,8 & 1,3 & 11,4 & 404,0 & $05: 45$ & 5,750 & 5,253 & $8,7 \%$ \\
\hline 2 & 3 & $19 /$ jan $/ 98$ & $\mathrm{~T} 1$ & 46,6 & 8,5 & 5,5 & $1.695,0$ & $06: 00$ & 6,000 & 3,285 & $8,3 \%$ \\
\hline 3 & 4 & $16 / \mathrm{fev} / 98$ & T3 & 18,4 & 2,0 & 9,2 & $1.141,0$ & $02: 40$ & 2,667 & 3,739 & $18,7 \%$ \\
\hline 4 & 5 & $09 / \mathrm{abr} / 98$ & T3 & 19,4 & 0,8 & 24,3 & 425,0 & $04: 20$ & 4,330 & 5,167 & $11,5 \%$ \\
\hline 5 & 6 & $31 / \operatorname{dez} / 98$ & $\mathrm{~T} 1$ & 59,6 & 1,2 & 49,7 & $7.230,0$ & $02: 45$ & 2,750 & 2,043 & $18,2 \%$ \\
\hline 6 & 8 & $30 / \operatorname{mar} / 99$ & T3 & 9,6 & 0,3 & 32,0 & 222,0 & $04: 45$ & 4,750 & 6,391 & $10,5 \%$ \\
\hline 7 & 9 & $21 /$ nov $/ 99$ & T3 & 70,6 & 7,8 & 9,1 & $2.150,0$ & 02:35 & 2,583 & 3,038 & $19,4 \%$ \\
\hline 8 & 10 & $07 / \mathrm{dez} / 99$ & $\mathrm{~T} 2$ & 83,6 & 1,7 & 49,2 & $5.968,0$ & $02: 15$ & 2,250 & 2,175 & $22,2 \%$ \\
\hline 9 & 11 & $29 / \mathrm{dez} / 99$ & $\mathrm{~T} 2$ & 13,8 & 0,5 & 27,6 & 884,0 & 05:15 & 5,250 & 4,065 & $9,5 \%$ \\
\hline 10 & 12 & $19 / \operatorname{mar} / 00$ & T3 & 4,0 & 0,7 & 5,7 & 326,0 & $04: 40$ & 4,667 & 5,636 & $10,7 \%$ \\
\hline 11 & 13 & $26 /$ nov $/ 00$ & T3 & 18,4 & 1,8 & 10,2 & 446,0 & $04: 25$ & 5,417 & 5,086 & $9,2 \%$ \\
\hline 12 & 14 & $12 / \operatorname{mar} / 01$ & $\mathrm{~T} 2$ & 29,7 & 4,7 & 6,3 & 707,0 & $04: 15$ & 4,250 & 4,374 & $11,8 \%$ \\
\hline 13 & 15 & $26 / \operatorname{dez} / 01$ & T3 & 9,0 & 0,8 & 11,3 & $1.047,0$ & $05: 35$ & 5,583 & 3,846 & $9,0 \%$ \\
\hline 14 & 16 & $04 / \mathrm{jan} / 02$ & $\mathrm{~T} 2$ & 16,8 & 0,3 & 56,0 & $1.110,0$ & $02: 50$ & 2,833 & 3,773 & $17,6 \%$ \\
\hline 15 & 18 & $01 /$ fev $/ 02$ & $\mathrm{~T} 2$ & 29,6 & 2,0 & 14,8 & $1.810,0$ & $03: 30$ & 3,500 & 3,215 & $14,3 \%$ \\
\hline 16 & 19 & $26 / \mathrm{mar} / 02$ & T3 & 47,6 & 1,3 & 36,6 & $1.304,0$ & $03: 45$ & 3,750 & 3,579 & $13,3 \%$ \\
\hline
\end{tabular}

Fonte: Produzida em conformidade com informações contidas em Drumond (2004)

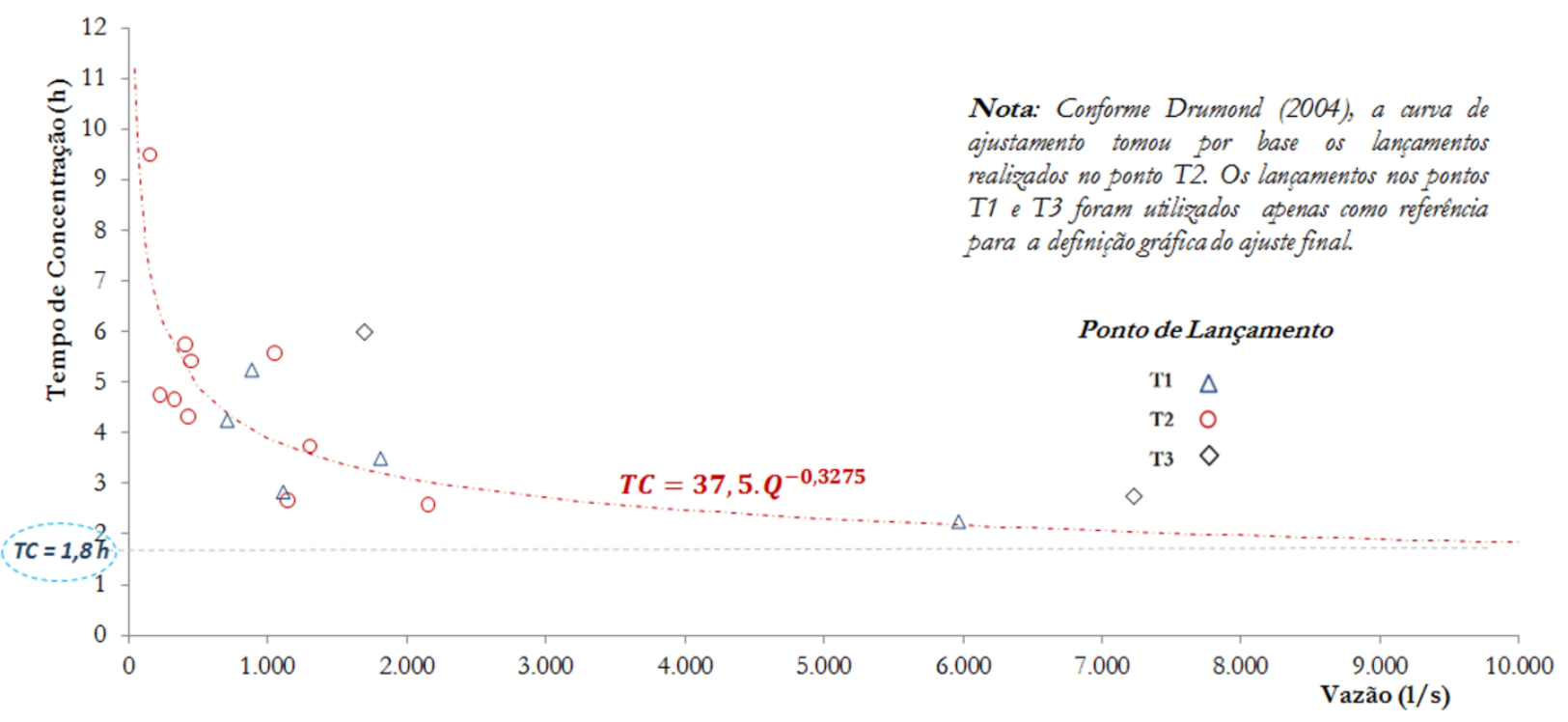

Figura 3 - BMF: Curva Ajustada - Tempo de Concentração x Vazão

Fonte: Adaptado de Drumond (2004) 
Amanthea e Nascimento: Urbanização de baixo impacto (LID): Uso de geotecnologias para estimativa do tempo de concentração de bacia em cenário de pré-desenvolvimento.

em confronto com vazões registradas:

$$
|\bar{e}|=\frac{1}{n} \cdot \sum\left|T C_{o b s}-T C_{\text {calc }}\right|
$$

O intervalo de tempo entre o lançamento e a passagem do pico de concentração do traçador na saída da BMF representa o tempo observado $\left(T C_{o b s}\right)$, como ilustra a medição realizada entre 07 e 10/12/99 (Figura 4).
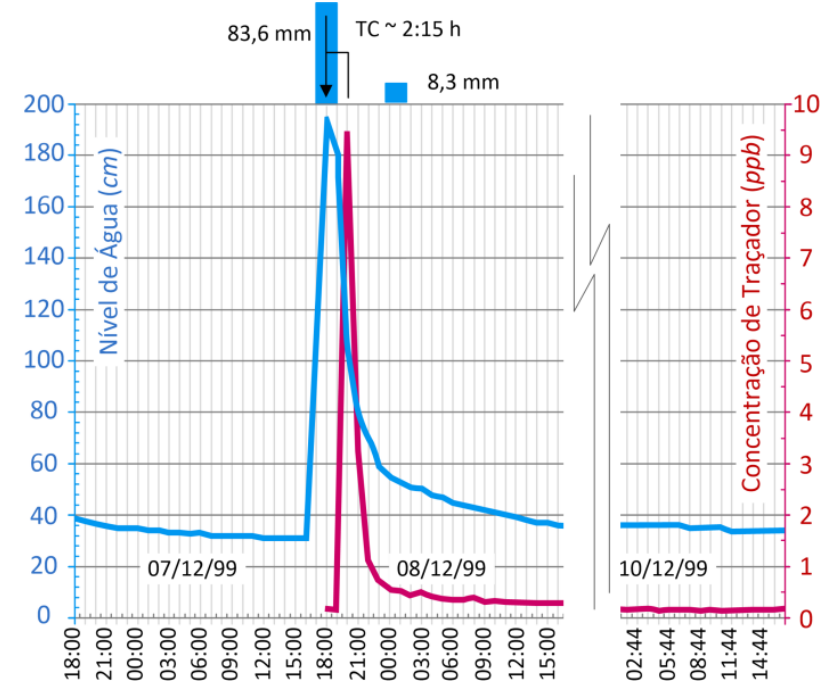

Notas:

1) Lançamento feito $\mathrm{em} 07 / 12 / 99$ as $17 \mathrm{~h}: 45 \mathrm{~min}$

2) Primeira amostra coletada em $07 / 12 / 99$ às $17 \mathrm{~h}: 58 \mathrm{~min}$

3) A precipitação indicada corresponde aos dados da Estação Fazenda Laranjeiras

Figura 4 - BMF: Medição direta de TC Fonte: Editado de Drumond (2004, p.236)

Se consideradas as 16 campanhas efetivas, o erro absoluto médio foi de $0,86 \mathrm{~h}$. Entretanto, esse valor cai para $0,4 \mathrm{~h}$, se admitidos apenas os eventos 5 e 8 (Tabela 1 - lançamentos em pontos distintos T1e T2) em que ocorreram precipitações antecedentes e chuvas intensas distribuídas por toda a bacia. Como o valor $1,8 \mathrm{~h}$ definido para o tempo de concentração corresponde a extremos de vazão (Figura 3), Drumond assumiu que o erro para o tempo de concentração seria de $0,4 \mathrm{~h}$. Portanto, o valor do TC definido para a BMF encontra-se dentro da faixa de $1,8 \mathrm{~h}+/-0,4 \mathrm{~h}$.

Em função da variabilidade significativa entre TC observados (Tabela 1), Drumond (2004) realizou também uma correlação dos TCs com períodos de retorno. Utilizando-se de análise de frequência para uma série com 21 eventos de vazões máximas anuais, registradas entre os anos hidrológicos de 1979-1980 a 2001-2002, conseguiu o melhor ajuste com a distribuição de Gumbel para máximos. Obteve, então, a relação entre período de retorno ( $\mathrm{T}[$ anos] $)$ e vazões de pico $\left(\mathrm{Q}\left[\mathrm{m}^{3} / \mathrm{s}\right]\right)$ :

$$
T=\frac{2,09}{\exp \left[-\frac{(Q-3,79)}{2,09}-\exp \left(-\frac{(Q-3,79)}{2,09}\right)\right]}
$$

Extraindo o valor de $Q$ em função de $T C$ a partir da curva ajustada (Figura 3) e substituindo na equação (1), chegou à relação entre período de retorno ( $\mathrm{T}[$ anos $]$ ) e tempo de concentração (TC [b]) dada pela equação (2).

$$
T=\frac{2,09}{\exp \left[-\frac{\left(64,1 \cdot T C^{-3,0534}-3,79\right)}{2,09}-\exp \left(-\frac{\left(64,1 \cdot T C^{-3,0534}-3,79\right)}{2,09}\right) \mid\right.}
$$

Constatou-se, portanto, que com o aumento de $T$ ocorre uma tendência de o TC ficar muito próximo do valor final estimado, como mostra a Tabela 2 , derivada da equação (2). Observa-se, na faixa de altos períodos de retorno (itens de 1 a 5), que, enquanto a variação do TC permanece constante e praticamente desprezível ( 6 minutos), $T$ sofre significativas e crescentes variações de décadas, chegando a 358,47 anos.

Tabela 2-BMF: Valores Numéricos de TC e T

\begin{tabular}{c|c|c|c|c}
\multirow{2}{*}{ Item } & $\begin{array}{c}\text { Tempo de } \\
\text { Concentração }(T C)\end{array}$ & $\begin{array}{c}\text { Período de } \\
\text { Retorno }(T)\end{array}$ & \multicolumn{2}{|c}{ Variação } \\
\cline { 3 - 4 } & $(b)$ & 505,75 & - & - \\
\hline 1 & 1,60 & 147,28 & 0,10 & 358,47 \\
\hline 2 & 1,70 & 55,77 & 0,10 & 91,51 \\
\hline 3 & 1,80 & 25,71 & 0,10 & 30,06 \\
\hline 4 & 1,90 & 13,77 & 0,10 & 11,94 \\
\hline 5 & 2,00 & 2,27 & 0,50 & 11,50 \\
\hline 6 & 2,50 & 2,00 & 0,06 & 0,27 \\
\hline 7 & 2,56 & 1,96 & 0,01 & 0,04 \\
\hline 8 & 2,57 & 1,92 & 0,01 & 0,04 \\
\hline 9 & 2,58 & 1,85 & 0,02 & 0,07 \\
\hline 10 & 2,60 & 1,55 & 0,10 & 0,30 \\
\hline 11 & 2,70 & 1,34 & 0,10 & 0,21 \\
\hline 12 & 2,80 & & & \\
\hline
\end{tabular}

\section{Métodos Empíricos e Semi-Empíricos}

Os métodos empíricos utilizados para estimativa de TC normalmente resultam da análise estatística de grandes volumes de informação de campo que conduzem à obtenção de equações de regressão. São rígidos e estáticos, não consideram a variabilidade espacial e temporal das características e procuram estabelecer uma relação entre o $T C$ e a fisiografia da bacia.

Tornaram-se os mais conhecidos e empregados porque são os mais simples, já que se utilizam apenas dos dados geométricos da bacia por tratar-se de modelos concentrados em relação à distribuição espacial. De forma bem geral, na prática da engenharia, a escolha do método empírico a empregar pode se caracterizar como arbitrária, já que nem sempre é clara a relação entre a bacia em estudo e aquela empiricamente analisada que embasou o método selecionado. Os métodos semi-empiricos apresentam maior flexibilidade de uso por incluírem parâmetros que variam com as condições biofísicas da bacia, caracterizando-se melhor como modelos espacialmente distribuídos. Possibilitam análises sob diferentes cenários e a previsão de comportamentos hidrológicos em função de alterações no uso do solo (MATA -LIMA et al., 2007; SHARIFI; HOSSEINI, 2011).

Dentre os métodos semi-empíricos recomendáveis para uso em sistemas de LID destacam-se os de velocidade ou cinemático $s$ por serem os mais apropriados, precisos e amplamente reconhecidos na análise de diferentes cenários de uso e ocupação de 
uma bacia hidrográfica. O método de velocidade TR-55 (Technical Release 55), do Natural Resources Conservation Service (NRCS), aqui chamado simplesmente de método de velocidade para determinação de TC (mvTC), possui uma base conceitual sólida para estimar a velocidade de fluxo. Ele tem sido comumente escolhido por sua flexibilidade e também como o mais preciso para o cálculo do TC em bacias hidrográficas urbanas e não urbanas (DAVIS; MCCUEN, 2005; DER, 1999; FANG et al. 2007; McCUEN et al., 1984; SHARIFI; HOSSEINI, 2011; USDA, 1986).

Apesar de idealizado para pequenas bacias, em teoria, pode ser aplicado em bacia de qualquer dimensão (McCuen et al., 1984). Em suas análises McCuen et al. (1984) verificaram evidências de uma estreita concordância entre o valor médio calculado pelo mvTC e aquele obtido a partir de dados de precipitação e hidrograma.

Métodos distribuídos como o mvTC foram criados para fornecerem melhores estimativas de TC. Buscam ser mais realistas na determinação do tempo de translado, intervalo necessário para um determinado volume de água escoar de um ponto a outro, e, também por isto, requerem um número maior de parâmetros de entrada (GREEN; NELSON, 2002; SHARIFI; HOSSEINI, 2011; WONG, 2009).

O mvTC considera para o cálculo de TC, além do caminho hidraulicamente mais longo percorrido pelo escoamento, o tipo de fluxo que se forma nesse trajeto. Pode ocorrer escoamento difuso sobre a superfície, chamado aqui de fluxo de rampa (sheet flow), fluxo de canal (channel flow) ou fluxo misto (shallow concentrated flow), relacionados respectivamente aos regimes de escoamento laminar, turbulento e de transição. Inicialmente pode ocorrer o fluxo de rampa, que após determinada distância, define seu curso em canais rasos (fluxo misto) até atingir o escoamento em canais (fluxo de canal). O processo de cálculo consiste na determinação do valor do tempo do trajeto de fluxo, considerados seus diferentes tipos, desde o ponto de referência até a saída da bacia. A soma dos tempos correspondentes aos fluxos de rampa, canal e misto, do trecho hidraulicamente mais longo, fornecerá o valor do TC. Na seção de Metodologia deste artigo o mvTC será oportunamente detalhado.

Muitos autores, a exemplo de Esteves e Mendiondo (2003), Fang et al. (2007, 2008), Grimaldi et al. (2012), Kliber e Aron (1993), Kobiyama et al.(2006), Liang e Melching (2012), Loukas e Quick (1996), Mata-Lima et al. (2007), McCuen et al. (1983, 1984), McCuen (2009), Papadakis e Kazan (1987), Sharifi e Hosseini (2011), Silveira (2005), Upegui e Gutiérrez (2011) e Wong (2005) realizaram estudos com o objetivo de classificar, avaliar, sistematizar, comparar valores ou estabelecer padrões entre métodos estimativos de TC, em geral também buscando identificar suas origens, suas principais características e selecionar quais métodos produziriam as estimativas mais confiáveis. Um ponto em comum é que a variação de resultados estimados por diversos métodos em geral mostra-se bastante expressiva, a exemplo dos estudos de Grimaldi et al.(2012) e Papadakis e Kazan (1987), em que as predições numéricas através de diferentes métodos variaram 500\%. McCuen et al. (1984), após analisarem 11 métodos e constatarem ampla margem de variabilidade entre valores computados, questionaram a validade de se continuar a utilizar fórmulas empíricas para estimativas de TC. A afirmação quase profética de McCuen et al.(1984) de que o verdadeiro valor do TC nunca será determinado ainda possui muita força em seu significado.

Considerando a importância do TC para análises hidrológicas, essas incertezas inerentes aos métodos tornam-se muito críticas, podendo implicar situações indesejáveis ou muito diferentes das previstas (MCCUEN; SPIESS, 1995). Fang et al. (2007) observam que a precisão na estimativa do TC tem implicações diretas no valor da vazão de pico, já que um TC superestimado pode implicar em vazão de pico subestimada.

\section{Geotecnologias para determinação do TC}

O geoprocessamento integra informações de bases de dados numéricas e espaciais em um modelo hidrológico específico de interesse em estudo (BILASCO, 2011). Através da visualização espacial dos resultados de cálculo, facilita a verificação de consistência dos dados e possibilita ampla análise pelo projetista.

Apesar do grande avanço da tecnologia há que se considerar que nem sempre imagens de alta resolução estarão disponíveis, principalmente em função dos custos envolvidos. Por isso, tanto a base de dados para gerar os modelos digitais de terreno (MDT)quanto os modelos digitais de elevação (MDE) devem ser manipulados criteriosamente.

Os modelos digitais que servem de base para a maioria das operações de geoprocessamento, geralmente apresentam falhas (pits, sinks, depressions) em quantidade inversamente proporcional às suas resoluções gráficas. Essas alterações artificiais de relevo podem criar descontinuidades nos padrões de drenagem e influenciar na resposta hidrológica do escoamento superficial da bacia. Há, portanto, a necessidade de utilização de mecanismos para correção dessas falhas. Contudo, durante esse processo de ajuste, deve haver também o devido cuidado na consideração das informações sobre a hidrografia natural da bacia. Dessa forma, evita-se a possibilidade de ocorrência indevida de áreas artificialmente planas que poderiam afetar a condição real do escoamento (GRIMALDI et al., 2007, PIRES et al., 2005). Em determinados processamentos também são recomendáveis ajustes pontuais em locais com erros evidentes. Isso se aplica, por exemplo, em falhas geradas por interpolação de borda, no contorno da bacia, onde o fluxo deveria seguir para o interior da mesma, mas comporta-se como se o divisor de águas estivesse deslocado, forçando o desvio de parte do escoamento para a bacia contígua.

\section{METODOLOGIA}

Para facilitar a descrição, nas próximas seções serão adotadas as definições a seguir:

a) Ponto de Concentração (PC) - O exutório, a saída ou a seção de estudo na bacia onde as águas se concentram; b) Tempo de Concentração Celular (TCcel) - Tempo que o fluxo demora a atingir o ponto de concentração partindo do ponto em análise, a célula de referência; c) Tempo de Concentração (TC) - Corresponde ao maior valor da série consistida de tempo de concentração 
celular (TCcel).Quando o PC receber o volume de água correspondente ao ponto com o maior TCcelda série consistida da bacia estará ocorrendo, simultaneamente, a contribuição de todos os pontos representativos da bacia; d) Tempo de Passagem (tp) - Tempo que um tipo de fluxo demora a atravessar uma célula qualquer; e) Tempo de trânsito celular - (Ttcel): Tempo de passagem (tp) correspondente ao tipo de fluxo predominante que passa por determinada célula; f) Tempo de Trânsito (Tt): Tempo que o fluxo leva para sair do ponto mais a montante, seguindo a direção de fluxo, até atingir a célula de referência; g) Modelo digital de terreno bidrologic amente consistido (MDT-HC) - Superfície sintética, obtida por interpolação, que representa a distribuição espacial da altimetria do terreno com variação contínua no espaço. Para a sua geração são consideradas, além das curvas de nível e pontos cotados, as informações relativas a lagos, depressões, canais de drenagem, entre outros elementos hidrográficos (RAMOS, 2013).

\section{Base de dados}

O MDT-HC foi gerado com resolução espacial de $5 \mathrm{~m}$ (Padrão de Exatidão Cartográfica - PEC, classe A). Utilizou a base cartográfica do Instituto de Geociências Aplicadas (IGA), escala 1:25.000, complementada através da hidrografia regional fornecida pelo Instituto Mineiro de Gestão das Águas (IGAM). Para o geoprocessamento adotou-se o sistema geodésico de referência SIRGAS 2000 (Sistema de Referência Geocêntrico para as Américas), com projeção UTM (Sistema Universal Transverso de Mercator), fuso 23S. Empregou-se o software ArcGis for Desktop v.10.2.2, com licença Advanced e o Python (software livre), linguagem interpretada de alto nível de programação que também integra o pacote do ArcGis. As soluções aqui apresentadas podem ser reproduzidas de forma semelhante por outros softwares livres, a exemplo do Spring, Quantum Gis, Terra View ou Grass.

Para a classificação da vegetação, uso e ocupação do solo utilizou-se o Google Earth, com variação de escalas (zoom) em até 1: 500. A qualidade das imagens nesse nível de escala permitiu ótima identificação de elementos. O desenho de cada componente de classe da área foi realizado com o uso de ferramentas avançadas do próprio Google Earth. As informações gráficas passaram por processo de vetorização seguido de geoprocessamento no ArcGis. Para dirimir eventuais dúvidas foram analisadas informações adicionais de campo, disponibilizadas pelo Centro de Desenvolvimento da Tecnologia Nuclear (CDTN) ou por SOARES, 2010.

Também foram utilizados dados de precipitação disponíveis pelo Hidroweb, da Agência Nacional de Águas (ANA) de 36 anos de observação do posto pluviométrico da Fazenda Laranjeiras, localizado na BMF.

\section{Método de Estimativa do TC}

Inicialmente, há a necessidade de se determinarem para todas as células da bacia os tempos de passagem (tp’s) para cada tipo de fluxo. O conjunto de células da bacia com ostp's, classificados por tipo de fluxo, corresponderá à matriz de elementos dos tempos de trânsito celular (Ttcel). A partir das matrizes deTtcel's e de direções de fluxo correspondentes determina-se, por geoprocessamento, a matriz de elementos TCcel'sda bacia. O elemento com o maior valor na matriz de TCcels corresponderá ao TC preliminar. Através de processo de classificação dos TCcel e de análise de consistência o valor final do $T C$ será então selecionado.

\section{Tempo de Passagem $(t p)$}

Com base em USDA (1986), os tempos de passagem por unidade de comprimento $[\mathrm{seg} / \mathrm{m}]$ para os escoamentos de rampa, canal e misto podem ser calculados, respectivamente, pelas equações:

$$
\begin{gathered}
\frac{t p_{\text {r rampa }}}{L}=\frac{328,536 \cdot n_{1}{ }^{0,8}}{P_{2}{ }^{0,5} \cdot I^{0,4} \cdot L^{0,2}} \\
\frac{t p_{-} \text {canal }}{L}=\frac{n_{2}}{R h^{\frac{2}{3} \cdot \sqrt{I}}} \\
\frac{t p_{-} \text {misto }}{L}=\frac{n_{3}}{R h^{\frac{2}{3}} \cdot \sqrt{I}}
\end{gathered}
$$

Onde:

tp_rampa[seg]: Corresponde a uma simplificação da fórmula da onda cinemática do tempo de concentração associada à equação de Manning. Refere-seà uma chuva efetiva estabelecida com intensidade constante e duração de 24 h (USDA, 1986); Manning;

tp_canale tp_misto[seg]: Correspondem à fórmula de

$L:$ comprimento de fluxo $[m]$ (distância máxima percorrida pelo fluxo a partir de montante até o ponto de referência); $I$ : declividade $[\mathrm{m} / \mathrm{m}]$;

$\mathrm{R} h$ : raio hidráulico $[\mathrm{m}]$;

Nota1: Para os locais com reservatórios ou lagos considerou-setp $=0$ (USDA, 1986, p.3-4). Nos pontos onde $I=0 \mathrm{ou} L=0$, admitiu-se também $t p=0$.

\section{Fluxo de Rampa}

$P_{2}:$ precipitação $[\mathrm{mm}]$ para $24 \mathrm{~h}$ com período de retorno de 2 anos (Para a BMF obteve-se $P_{2}=80,04 \mathrm{~mm}$ com base em 36 anos de observação do posto Fazenda Laranjeiras);

$n_{1}$ : coeficiente de rugosidade (Manning) para fluxo de rampa (ALVAREZ, 2006, p.307; ENGMAN, 1986, p.49; USDA, 1986, p.3).

\section{Fluxo de Canal}

$n_{2}$ : coeficiente de rugosidade (Manning) para canais (Tabela 03) estimado pelo Método Cowan de acordo com Chow (1959, p.109), citado também por Baptista e Coelho (2010, p.240). 
Tabela 3 - BMF: Rugosidade $n_{2}$ estimada

\begin{tabular}{c|c}
\hline Condições do canal & $\boldsymbol{n}_{2}$ \\
\hline $\begin{array}{c}\text { Material envolvido }\left(m_{0}\right): \\
\text { solo-rocha }\end{array}$ & 0,023 \\
\hline $\begin{array}{c}\text { Grau de irregularidade }\left(m_{1}\right): \\
\text { severo }\end{array}$ & 0,020 \\
\hline $\begin{array}{c}\text { Variaģões da segão transversal }\left(m_{2}\right): \\
\text { alternâncias frequentes }\end{array}$ & 0,015 \\
\hline $\begin{array}{c}\text { Eeito de obstrugões }\left(m_{3}\right): \\
\text { pequeno }\end{array}$ & 0,015 \\
\hline $\begin{array}{c}\text { Vegetação }\left(m_{4}\right): \\
\text { alta }\end{array}$ & 0,050 \\
\hline $\begin{array}{c}\text { Grau de meandrização }\left(m_{5}\right): \\
\text { pequeno } \\
4\end{array}$ & 1,000 \\
\hline$n_{2}=\left(\sum_{i=0}^{4} m_{i}\right) \cdot m_{5}$ & 0,123 \\
\hline
\end{tabular}

Nota 2: Para a determinação do raio hidráulico em fluxo de canal admitiu-se, como hipótese simplificadora, a predominância de ocorrência de canais triangulares de seção $1 \mathrm{~V}: 2 \mathrm{H}$

\section{Fluxo Misto}

$n_{3}$ : coeficiente de rugosidade (Manning) para fluxo misto, adotado $\mathrm{n}_{3}=0,05$ (USDA, 1986, p. F-1).

Nota 3: Considerando também que para superfícies não pavimentadas a velocidade $v[\mathrm{~m} / \mathrm{s}]$, segundo USDA (1986), é determinada pela equação (6):

$$
v=4,9178 \cdot \sqrt{I}
$$

Pode-se obter então por Manning o raio hidráulico (Rh)

$$
R h=10,906 \cdot n^{1,5}
$$

Assim, para $n_{2}=0,05$, a equação (5) pode ser reescrita na forma da equação (8):

$$
\frac{t p \_ \text {misto }}{L}=\frac{0,203}{\sqrt{I}}
$$

\section{Tempo de Trânsito Celular (Ttcel)}

O tempo de trânsito celular corresponde ao tempo de passagem por UNIDADE de comprimento (tp/L), devidamente classificado por tipo de fluxo (tp_class), multiplicado pelo comprimento do fluxo na célula ou comprimento celular (Lcel):

$$
\text { Ttcel }=(\text { tp_class } / \mathrm{L}) . \mathrm{L} \text { cel }
$$

Para determinação dos TtcePs, os tp’s foram classificados (tp_class) segundo os critérios:

tp_rampa_class:A predominância do fluxo de rampa é estabelecida pela equação (3) para L $\leq 100 \mathrm{~m}$ (USDA, 1986);

tp_canal_class: A determinação do fluxo de canal foi realizada de forma interativa por geoprocessamento, adotandose a equação (4) com variação da área contribuinte $(A)$ para a formação do escoamento. $\mathrm{O}$ valor aceito corresponde à situação em que o fluxo de canal coincide com os levantamentos de campo disponíveis. No caso da Bacia do Mato Frio, os canais simulados por geoprocessamento para diversos valores de área contribuinte foram confrontados com mapas hidrográficos do IGA. Conclui-se que para a BMF o fluxo de canal ocorre para $A \geq 80.000 m^{2}$.Portanto,para essa condição, a equação (4) define o th_canal_class.

Tp_misto_class: Pode ser definido através da equação (8), para as regiões da BMF onde não predominam os fluxos de rampa ou canal.

A matriz dos Ttcels será então formada pela união de todos os tp's_class/Lx Lcel.

\section{Restrições ao $m v T C$}

Entre as principais críticas encontradas na literatura técnica, que despertam incertezas em relação ao uso do $m v T C$, destacam-se as seguintes:

I Pela definição adotada pelo USDA (1986), o TC é estabelecido com um único valor. Um único ponto, hidraulicamente mais distante, torna-se, pela definição, o eleito para representar uma bacia hidrográfica em sua plenitude (Fang et al., 2007; Grimaldi et al., 2012);

II Subjetividade na escolha das variáveis de entrada do método pelos projetistas (Fang et al., 2007; Grimaldi et al., 2012). Fang, Pradhan e Malla (2007) verificaram, por análise de sensibilidade das variáveis, que o comprimento de fluxo (L) e a rugosidade de Manning (n) representam os mais importantes parâmetros para estimativa pelo $m v T C$;

III A qualidade, a resolução espacial e a forma de utilização de modelos digitais de terreno em cálculos de geoprocessamento podem produzir alterações no valor final de TC (Grimaldi et al., 2012).

V I Possibilidade de se subdimensionar o $T t_{\text {misto }}$ por superestimação de velocidades quando as declividades são superiores a 4\% (Grimaldi et al., 2012);

V A não consideração do efeito de armazenamento nos canais pode subestimar o valor de TC (MCCUEN, 2009; GRIMALDI et al., 2012).

O método de velocidade TR-55 do NRCS foi selecionado neste estudo devido ao seu uso constar das recomendações em manuais de LID e também por ser um dos mais indicados no fornecimento de estimativas precisas e confiáveis, o suficiente para que se possa tratar o valor calculado como referência na verificação de outros métodos estimativos (DER, 1999; IOWA, 2008; MCCUEN et al., 1984; MCCUEN, 1998; NYS, 2010; SHARIFI; HOSSEINI, 2011).

Modificações foram aqui introduzidas a fim de se reduzirem as limitações do mvTC. Por facilidade de descriçãoserá denominado $\operatorname{mvTC}_{M}$ (método de velocidade modificado para o cálculo de TC). 
Amanthea e Nascimento: Urbanização de baixo impacto (LID): Uso de geotecnologias para estimativa do tempo de concentração de bacia em cenário de pré-desenvolvimento.

\section{Critérios Adotados para o $m v T C_{M}$}

De acordo com Grimaldi et al. (2012), o mvTC pode ser melhorado pela seleção apropriada do ponto hidraulicamente mais distante. Ampliando-se essa linha de raciocínio, realizou-se a principal modificação que corresponde ao conceito adotado neste trabalho para o TC, (definição exposta na alínea "c", da seção principal de Metodologia), minimizando-se a limitação apontada no item "I" - (único ponto define o TC).

Procurou-se reduzir as restrições "II" (subjetividade na escolha de valores de entrada) e "III" (resolução espacial) com criteriosa seleção dos dados de entrada pela forma, já descrita, de classificação das imagens e critérios para geração do modelo digital de terreno, produzindo-se um MDT-HC (definido na alínea "g").

Para se atenuar a restrição "IV" (superestimação de velocidades) foram acatadas as recomendações de McCuen et al.(1984), McCuen (2009) e Fang et al. (2007) com a apropriação da correção da velocidade no cálculo do $T t_{\text {misto }}$ de (GRIMALDI et al., 2010; GRIMALDI et al., 2012).

Desta maneira, o cálculo do tempo de passagem para fluxo misto foi produzido a partir da equação (8).

$$
\frac{t p \_ \text {misto }}{L}=\frac{0,203}{\sqrt{\bar{I}}}
$$

onde:

$$
\begin{aligned}
& \bar{I}=0,05247+0,063635 \cdot I-0,182 \cdot e^{-6238 \cdot I} \text { para } I>0,04 \\
& \bar{I}=I \text { para } I=\leq 0,04
\end{aligned}
$$

De acordo com a restrição do item "V" (efeito de armą̧enamento), por não se considerar o efeito de armazenamento em canais pode-se, eventualmente, subestimar o valor estimativo do TC em uma bacia.

Em condições normais, a urbanização convencional sempre reduzirá o valor de $T C$ em relação à situação de pré-desenvolvimento. Assim, para efeito de planejamento de empreendimentos de baixo impacto de urbanização torna-se bastante razoável a aceitação da estimativa pelo $m v T C_{M}$ do $T C$ como indicador a ser igualado ou superado.

\section{Geoprocessamento}

O geoprocessamento, através do ArcGis, pode ser totalmente automatizado, utilizando integralmente os recursos da linguagem Python. Por questões didáticas, serão mostrados os principais processamentos na forma convencional no ArcGis. Os passos iniciais que geraram as variáveis necessárias ao cálculo de TCcel estão representados na Figura 5. Em seguida foram gerados e posteriormente classificados os tempos de passagem por unidade de comprimento, para produzir os tempos de trânsito celular (Figura 6A).

Para a criação da matriz de elementos TCeel foram desenvolvidas duas funções no Python, a adiciona e aprox_cel. A primeira (Figura 6A) coleta todos os valores de Ttcel na direção de fluxo, desde a célula de referência até o PC.A segunda (Figura 6B) fornece os índices da célula vizinha para a qual o fluxo será direcionado, dependendo do valor da direção de fluxo $(D F)$ da célula de referência.

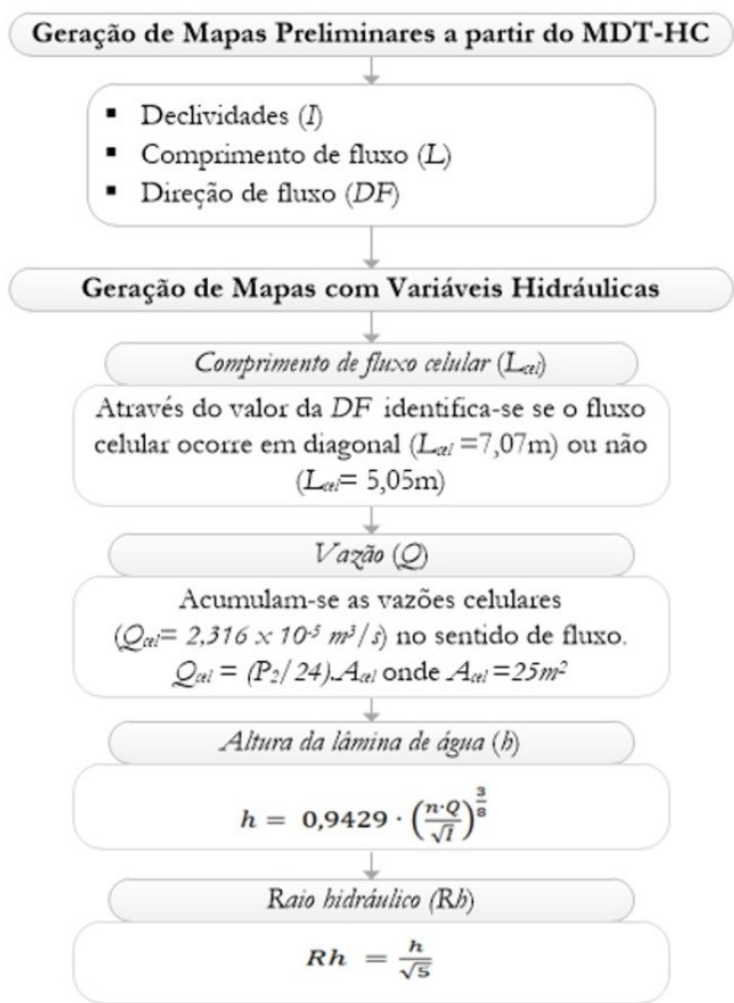

Figura 5 - BMF: Passos iniciais do geoprocessamento

O cálculo e a espacialização do TCcel ocorrem no módulo principal do Python (Figura 6D), em que todas as células da bacia são processadas e de onde o valor máximo de TCcel é extraído, em conformidade com o conceito tradicional de tempo de concentração.

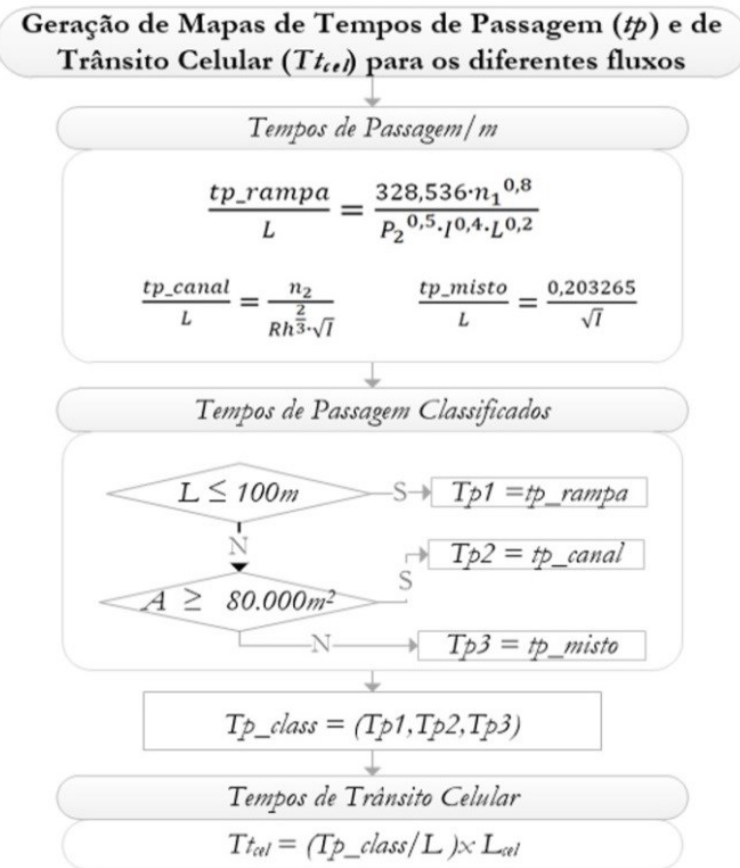

Figura 6A - Geração dos Tempos de Trânsito 


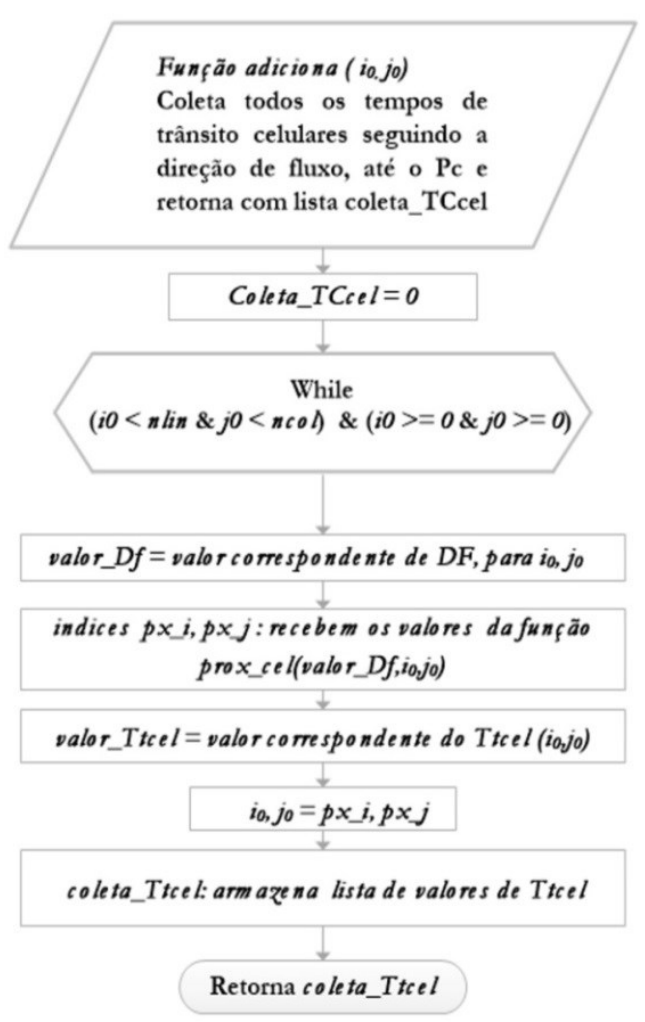

Figura 6B - Função adiciona

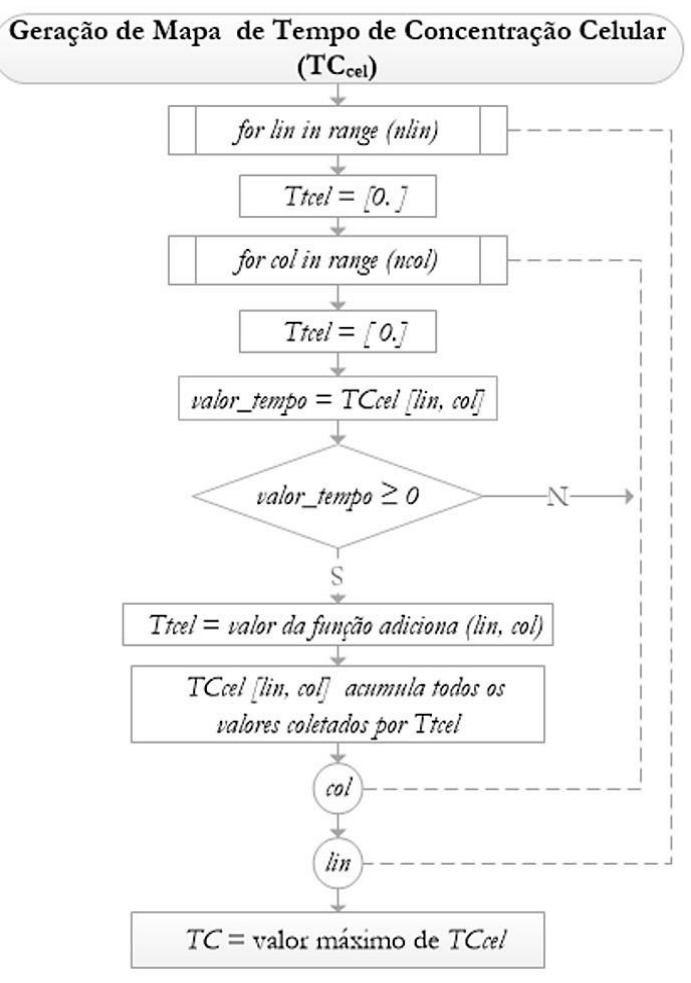

Figura 6D - Módulo Principal

As tabelas de I1 a I4 sintetizam as operações de geoprocessamento e facilitam a compreensão dos detalhes para a reprodução de cada etapa pelo leitor.

Tabela I1 - Cálculos Preliminares

Geração MDT-HC, Declividade I, Comprimento de fluxo L.

1.1 Geração do MDT-HC preliminar(MDT-HCp): [3D Analyst Tools/Raster Interpolation/Topo to Raster] - Input: curvas de nível, pontos cotados, contorno da bacia, rede de drenagem e lagos - Output surface raster: MDT-HCP

Output cell siže: função da escala $E$ (adotada maior precisão admissível: $0,2 \mathrm{~mm} \times \mathrm{E}$ ) - Margins in cells: valor zero (porque as curvas ultrapassam o limite da bacia, mitigando problemas de interpolação de borda) - Tolerance 1: (relativa a depressões) valor adotado 5: metade da distância entre curvas de nível, $10 \mathrm{~m}$ - Tolerance 2: (relativa a elevações) valor adotado 500:5 x a distância entre curvas de nível.1.2 Geração do MDT-HC: [Spatial Analyst Tools/Hydrology/Fill - Input. arquivo rasterMDT-HCp gerado - Output: MDT-HC. 1.3 Cálculo da Declividade: [3D Analyst Tools/Raster Surface/Slope] - Input. arquivo rasterMDT-HC-Output measurement: Percent_Rise - $Z$ factor. 1

1.4 Determinação das direções de fluxo: [Spatial Analyst Tools/Hydrology/Flow Direction] - Input. MDT-HC - Output. arquivo raster de direção de fluxo $(D F)$. 1.5 Determinação do comprimento do trajeto de fluxo superficial (L):[Spatial Analyst/Tools/Hvdrologv/Flow Length] - Input: DF - 
Tabela I2 - Cálculos Intermediários

Comprimento máximo de fluxo celular Lcel, Vazão produzida por uma célula Qcel, Vazão acumulada Q, Altura da lâmina d'água h, Raio bidráulico $\mathrm{R} h$.

2.1 Cálculo de Lcel:[SpatialAnalyst Tools/Conditional] - Con ("DF"=2 OR "DF"=8 OR "DF"=32 OR "DF"=128, 7.07, 5): se o valor da direção de fluxo for par, $L$ cel $=$ diagonal $=7,07 \mathrm{~m}$, senão $L c e l=$ Lado da célula $=5 \mathrm{~m}-$ Output $:$ Lcel

Tabela I2 - Cálculos Intermediários:Comprimento máximo de fluxo celular Lcel, Vazão produzida por uma célula Qcel, Vazão acumulada Q Altura da lâmina d'água h, Raio bidráulico Rh.

2.2 Cálculo de Qcel: Precipitação máxima de $24 \mathrm{~h}$ com período de retorno de 2 anos $\left(P_{2}\right): 80,04 \mathrm{~mm}$ - Área da célula $(5 \mathrm{x} 5 \mathrm{~m})($ Ace $): 25 \mathrm{~m}^{2}$

Qcel $=\left(P_{2} / 24\right) \times$ Acel $\times 10^{-3} / 3600=2,316 \times 10^{-5} \mathrm{~m}^{3} / \mathrm{s}$

2.3 Cálculo de Q:[Spatial Analyst Tools/Hydrology/Flow Accumulation] - Input flow direction raster: DF - Output Accumulation Raster: Q - Input weight raster: Qcel - Coeficiente de rugosidade para fluxo canalizado adotado: $\mathrm{n}_{2}=0,123$

2.4 Cálculo de $\boldsymbol{h}$ e Rh: [Spatial Analyst Tools/Map Algebra/Raster Calculator] - Adoção de seção de canal triangular $1 \mathrm{~V}: 2 \mathrm{H}$ - Output: $h, \mathrm{R} h$.

2.5 Determinação de $n_{1}$. [Conversion Tools/To Raster/Feature

Tabela I3 - Cálculos de Tempos de Passagem tp e de Trânsito Celular Ttcel (fluxos de rampa, de

3.1 Tempos de passagem/m (tp_L) do fluxo pela célula: [Spatial Analyst Tools/Map Algebral Raster Calculator]

3.2 Classificação dos tempos de passagem

[Spatial Analyst Tools/Conditional] - tp_rampa_class/L:

$[C o n(L<=100$, tp_rampa $)]-$ Output. tp_rampa_class_L

- Cálculo da área acumulada $\left(\mathrm{A}_{\mathrm{cc}}\right)$ segundo direção de fluxo [Spatial Analyst Tools/Hydrology/Flow Accumulation] - Input flow direction raster: DF - Output Accumulation Raster: $A_{c c}$ - Input weight raster: Acel tp_canal_class $/ L:[C o n(A c c \geq 0.08$, th_canal) Output.tp_canal_class_L]. $\bullet$ tp_misto_class $/ L$ :

[Con (IsNull ("tp_rampa_class") OR IsNull("tp_canal_class"), "tp_misto_class)"] - Output: tp_misto_class_L ${ }^{-}$Operações para atribuição de valores nulos às células com "NoData" para todos os tipos de this classificados (i=rampa, canal, misto) - [Con (IsNull ("tpi_class_L"), 0, tpi_class_L)]- Saídas: tp1_rampa_class, tp2_canal_class, tp3_misto_class. $\bullet$ Criação de Mosaicotp_class $/ L$, integrando todos os tempos de passagem classificados e ajustados (tp1_rampa_L, tp2_canal_L etp3_misto_L): [Data Management Tools $\backslash$ Raster $\backslash$ Raster Dataset $\backslash$ Mosaic To New Raster] - Mosaic operator: Mean - Tamanbo da Célula: $5 \times 5 \mathrm{~m}$ Pixel Type: 32 bits float - Output. tp_class_L・Atribuição de valor nulo para tp_class_L em locais com lagos ou reservatórios (criado previamente um rastertp_lagos com valores de pixels nulos onde existem lagos e NoData, sem ocorrência): [Spatial Analyst Tools/Map Algebral Raster Calculator] - tp_class_L $\times$ IsNull(tp_lagos) -

Output: TP1234_class. 3.3 Tempos de trânsito celular: [Spatial Analyst Tools/Map Algebra/Raster Calculator];Ttcel = TP1234_class $\times$ Lcel

\section{Análise de Consistência do TC}

Após a determinação por geoprocessamento do valor máximo de TCcel (TC preliminar), a série de valores de TCcel foi dividida em classes para se analisar, por distribuição de frequência, a eventual presença de outliers e a influência de cada intervalo de classe em relação à área da bacia. Considerando-se o intervalo de tempo mínimo de 600 segundos $(10 \mathrm{~min})$ utilizado no monitoramento na BMF e a amplitude da distribuição de TCcel 's, optou-se por dividir a amostra em 24 classes utilizando, através do ArcGis, o algoritmo de Jenks (Natural Breaks). Por meio de processo de cálculo, que considera os erros correspondentes à soma dos desvios absolutos sobre a mediana de classe, o Natural Breaks busca o estabelecimento de quebras naturais da série constituída por TCcel's para então promover o agrupamento dos dados com menor variação. Dessa forma, minimiza a variância intraclasses e maximiza a variância interclasses (GIRARDI, 2008).

Em seguida, atribuiu-se uma cor única para todas as classes (preto). Iniciou-se, manualmente, a alteração de cor (amarelo), partindo-se da classe com maiores valores de TCcel (classe 24) para as imediatamente anteriores, observando-se no mapa, a cada nova inserção de cor amarela, a repercussão visual na área total da bacia.

Posteriormente, foram realizados cálculos complementares para determinação das áreas e confirmação das evidências visuais que destacam a presença de outliers e de regiões com altos valores de TCcel, mas sem representatividade na área total da bacia. Dessa forma, células muito distantes, mas pouco significativas na formação do escoamento e que demandam um tempo expressivo para atingir o $P C$ deixam de mascarar o valor final do TC.

A classificação também possibilita identificar possíveis distorções relativas à base de dados que originou o MDT-HC, permitindo um refinamento domodelo digital previamente ajustado pelos mapas hidrográficos da bacia. Assim, de maneira interativapara efeito de cálculo do TC, o método também proporciona facilidades para o ajuste de pequenas distorções e descarte de pontos não significativos. O maior valor de TCcel do intervalo representativo de valores consistidos corresponderá ao $T C$ estimado pelo método $m v T C_{M}$

\section{RESULTADOS}

O processo de análise de consistência para a seleção do TCé um significativo diferencial do $m v T C_{M}$ em relação a outros métodos. De acordo com a metodologia empregada, cabe ao projetista tomar a decisão pela escolha do TC representativo da bacia. AFigura 08 apresenta os resultados dessa análise da série de valores de TCcel gerados por geoprocessamento. Observamse os TCcel's (amarelo) considerados outliers (gráfico B), seja por problemas nos dados que geraram o MDT-HC ou pela pouca representatividade em relação à área ocupada (gráfico $A$ - mapa (amarelo) e percentuais de área).

Desprezados os valores máximos das classes não representativas (16 a 24), o maior valor de TCcel entre os dados consistidos $(6.673 \mathrm{seg}$. ou 1,9 h. $)$ corresponde ao TC estimado 


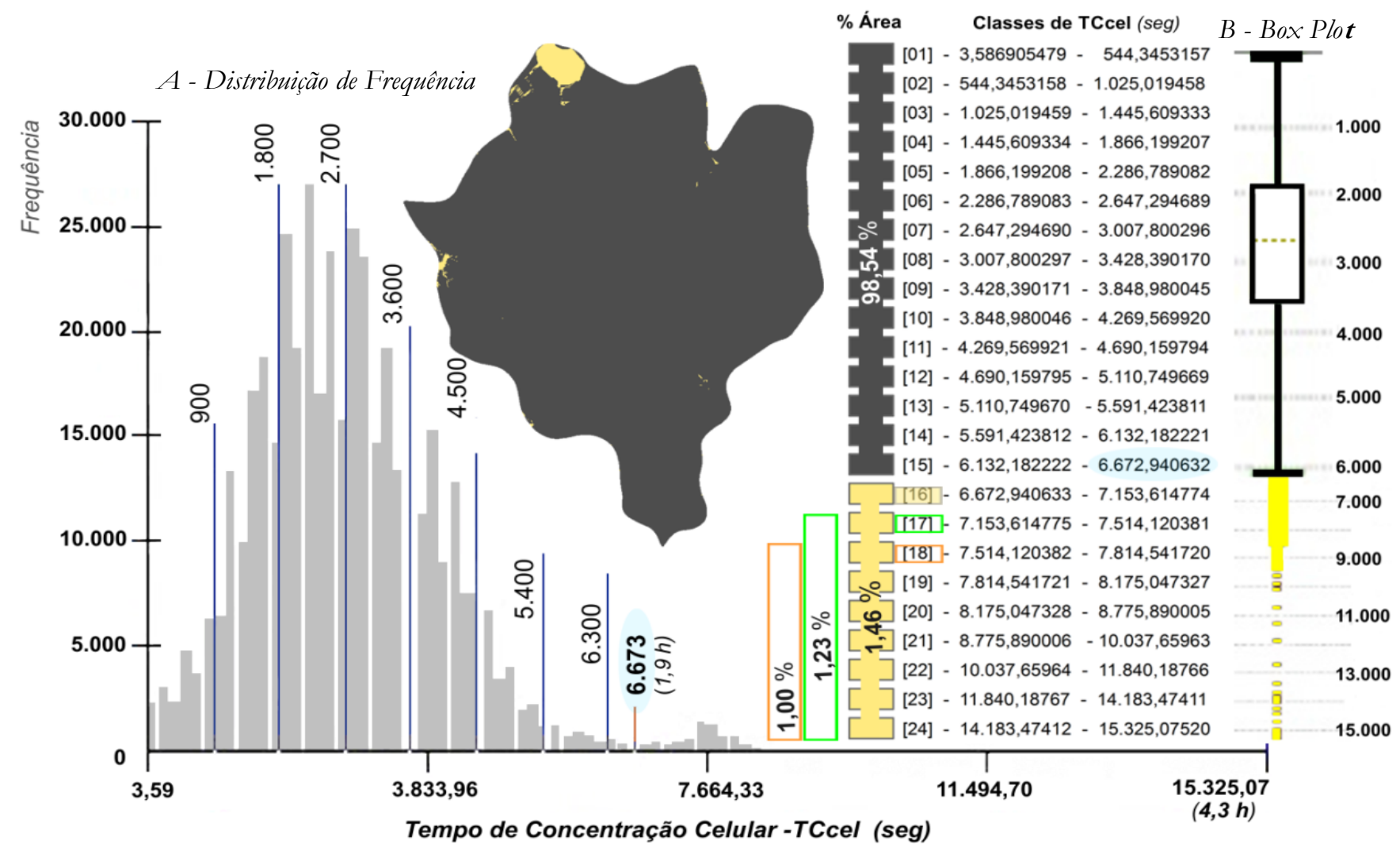

Figura 8 - Análise de consistência da série de valores TCcel

para a BMF. Esse valor de TC representa o tempo para que $98,54 \%$ da bacia contribua no ponto de concentração (PC). O gráfico $A$ (Figura 8 ) indica também a influência de área que haveria, caso o valor escolhido estivesse nos limites superiores das classes 16 ou 17.Ressalte-se que, se considerado o ponto hidraulicamente mais distante (a contribuição de 100\% da bacia), o maior valor da série de TCcel seria de 15.325,07 seg. ou 4,3h. Em síntese, pela definição usual $98,54 \%$ da área contribuinte levaria $1,9 \mathrm{~h}$ para atingir o $P C$ e os $1,46 \%$ restantes, mais $2,4 \mathrm{~h}$ !

Os mapas gerados a partir de geoprocessamento de informações da BMF, mostrados nas figuras a seguir, correspondem à classificação do uso do solo (Figura 9), às declividades (Figura 10), aos coeficientes de rugosidade para fluxos de rampa (Figura 11), tipos de escoamento (Figura 12) e tempos de concentração celular (Figura 13).

A Figura 13, representando o mapa da espacialização de TCcel ajustado e em classes com intervalos de 15 minutos, destaca a porção correspondente a $\mathbf{1 , 5 \%}$ da área da bacia que, com seus valores superiores ao TC estimado $(6.673 \mathrm{seg})$, seria responsável pela majoração em $126,32 \%$ do valor estimado para o TC pelo $m v T C_{M}$.

McCuen et al. (2009) afirmam que diferentes propósitos podem conduzir a diferentes métodos de se estimar TC. Cabe ao projetista escolher as ferramentas adequadas que lhe ofereçam mais informações para a tomada de decisão.

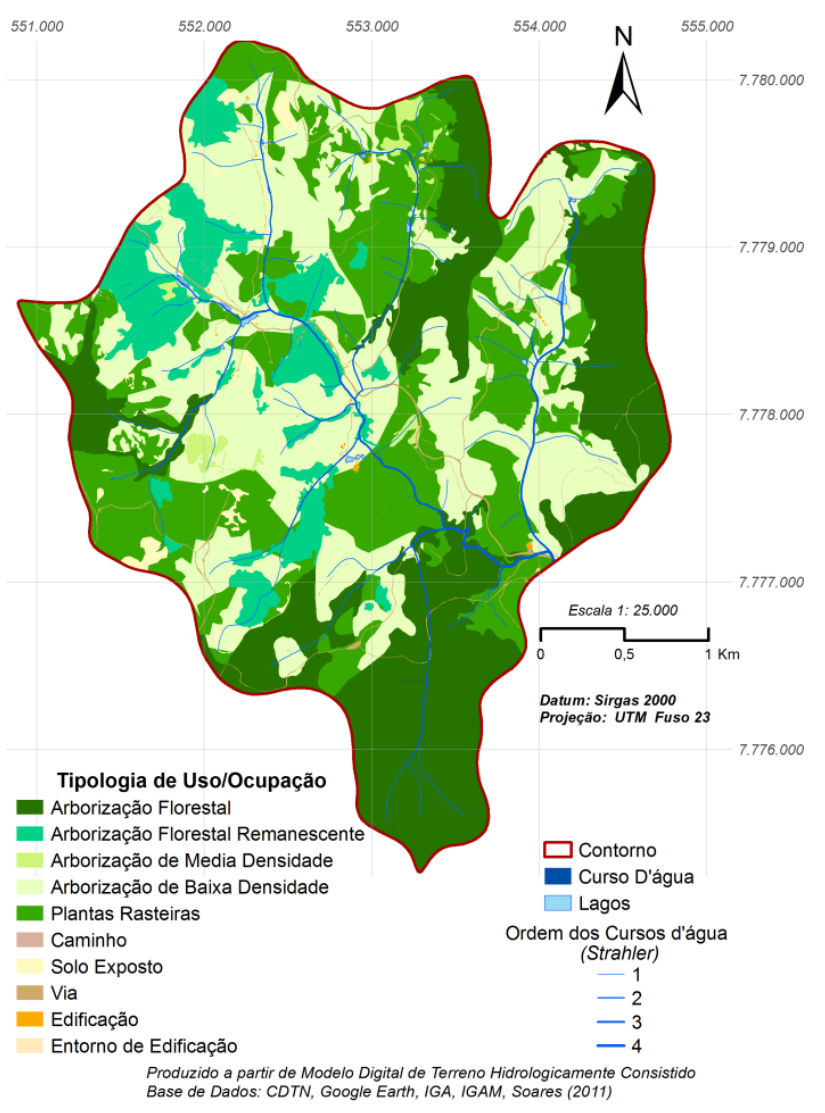

Figura 9 - BMF: Classificação do Uso e Ocupação do Solo 
Amanthea e Nascimento: Urbanização de baixo impacto (LID): Uso de geotecnologias para estimativa do tempo de concentração de bacia em cenário de pré-desenvolvimento.

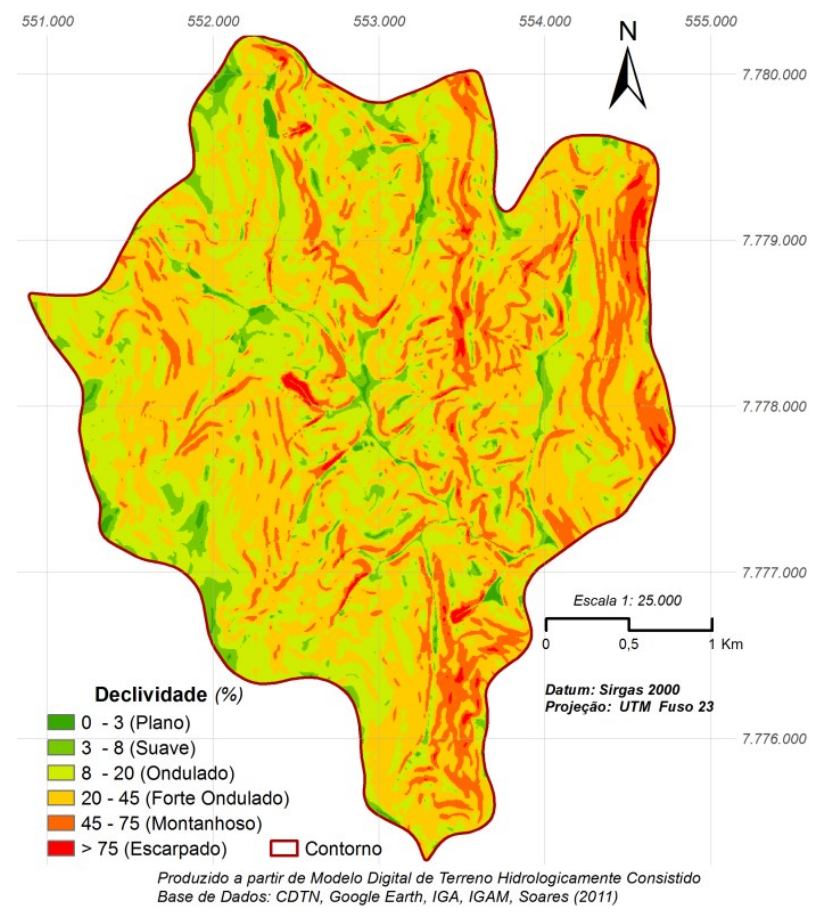

Figura 10 - BMF: Declividades

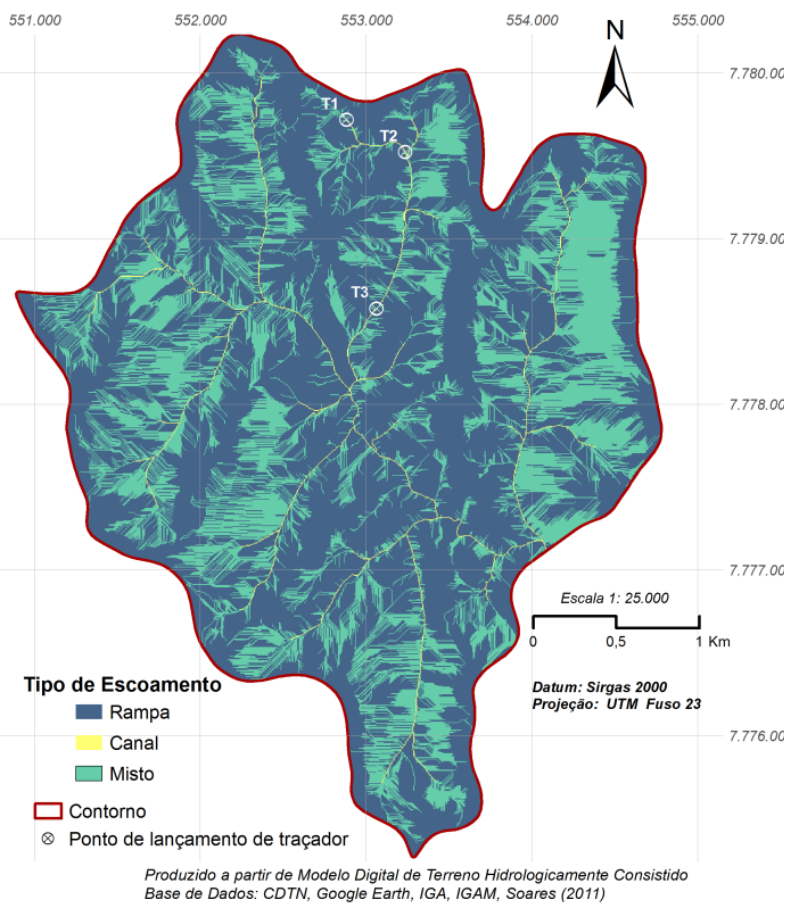

Figura 12- BMF: Tipos de Escoamento

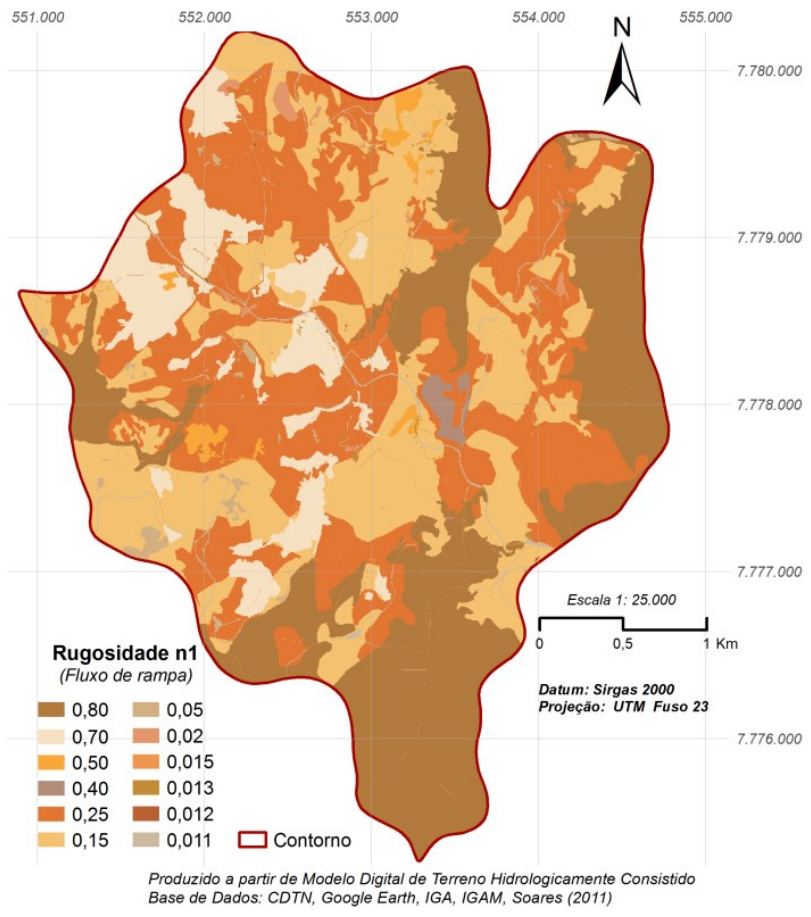

Figura 11 - BMF: Rugosidade n1 para fluxo de rampa

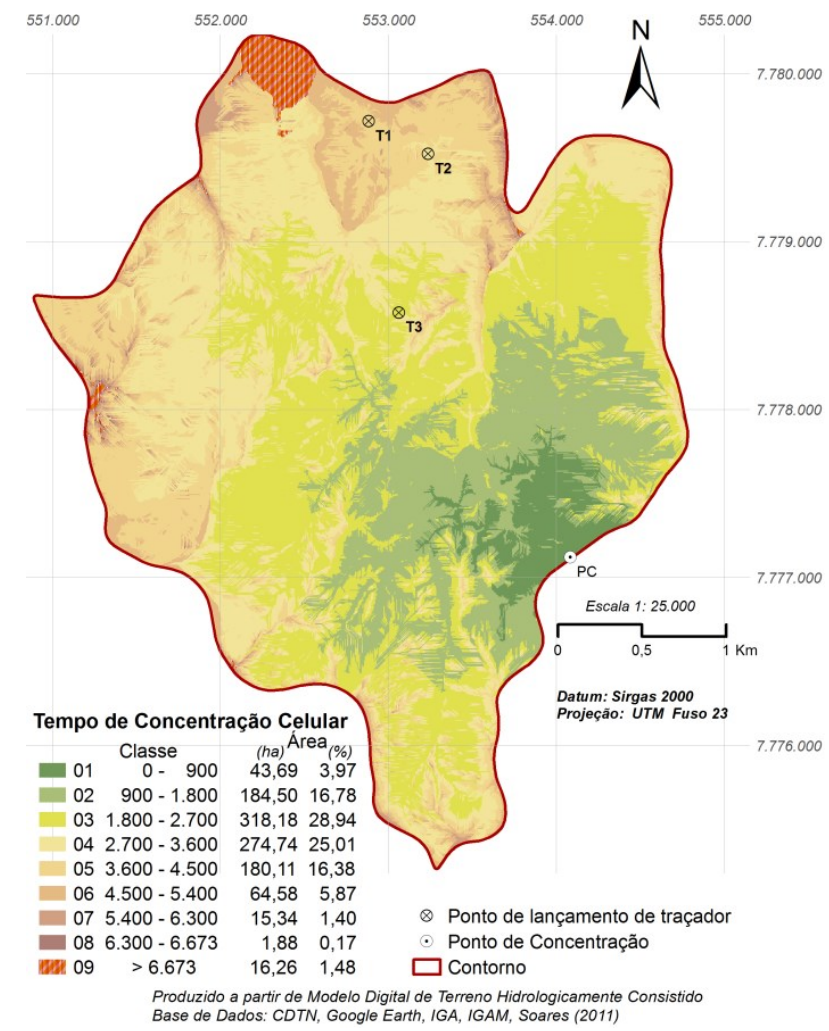

Figura 13 - BMF: Tempos de Concentração Celular 


\section{Confronto dos Resultados com a Medição Direta}

Com o objetivo de se estimular maior discussão em trabalhos futuros sobre a medição direta na BMF realizada por Drumond (2004) e, também, sobre este método estimativo do TC empregado, buscou-se traçar um paralelo entre os resultados obtidos e os observados.

De acordo com as informações sobre a medição direta do TC realizada na BMF, constantes na Figura 3 e Tabela 1, Drumond (2004) estimou que o valor final do $T C(1,8 \mathrm{~h}$ para a $\mathrm{BMF}$ )deveria estar contido na faixa entre 1,4 a $2,2 \mathrm{~h}$. Observa-se inicialmente uma coincidência numérica pela proximidade dos valores de $T C$ estimados por Drumond $\left(1,8\right.$ h)e pelo $m v T C_{M}(1,9 \mathrm{~b})$.

Analisando-se os mapas das figuras 12 e 13, constatase que a medição direta foi realizada, exclusivamente, a partir de pontos com fluxo de canal (pontos $T_{1}, T_{2}$ e $T_{3}$ ). Verifica-se ainda, pela Figura 3, que o ponto $T_{2}$ foi determinante para o ajuste da curva dos valores observados e, consequentemente, para a estimativa do valor final de TC por (DRUMOND, 2004).

Os valores de TCcel calculados pelo $m v T C_{M}$ correspondentes aos pontos $T_{1}, T_{2}$ e $T_{3}$ foram, respectivamente, 1,14h,0,94h e 0,64 h. Concentrando-se a atenção apenas no valor de $T_{2}(0,94 h)$, ponto efetivamente empregado para a estimativa de $T C$ por Drumond, nota-se que corresponde a $70 \%$ do valor mínimo da faixa recomendada pela medição direta, porém dentro do limite de erro absoluto médio obtido através de todas as campanhas discriminadas na Tabela 1.

Antes de uma comparação mais efetiva dos resultados, convém ressaltar que o $m v T C_{M}$ realiza cálculos com precipitação máxima de 24h para período de retorno de 2 anos (80,04 $\mathrm{mm}$ para a BMF). Além disso, para gerar o escoamento conforme USDA (1986) atribuiu-se uma intensidade pluviométrica constante (duração de $24 \mathrm{~h})$ de $3,34 \mathrm{~mm} / \mathrm{h}(80,04 \mathrm{~mm} / 24 \mathrm{~h})$. O contraste marcante fica estabelecido através do evento 8 , em destaque na Tabela 01, o mais representativo das campanhas de Drumond (2004), que se refere a uma intensidade de precipitação de 49,2 $\mathrm{mm} / \mathrm{h}$.

Em princípio, parecem estranhas essas proximidades numéricas de valores de TC (experimental x teórico), uma vez que as intensidades pluviométricas dos eventos em comparação são muito diferentes. Todavia, uma abordagem complementar dos conceitos envolvidos pode esclarecer melhor essa questão.

Para gerar o escoamento superficial direto na BMF, um evento teórico do $m v T C_{M}$ produz em uma hora, de acordo com os pressupostos desse método, uma precipitação efetiva de $3,34 \mathrm{~mm}$.

O evento 8 (Tabela 1), em uma hora, produziu uma precipitação total de 49,2mm. Torna-se necessário, portanto, o conhecimento da precipitação efetiva causada pelo evento 8 nesse intervalo de tempo.

Drumond (2008) realizou o balanço hídrico da BMF utilizando-se dos registros de monitoramento da Estação Fazenda Laranjeiras da BMF e de dados experimentais de infiltração no solo com o uso de traçador radioativo (Trítio), chegando aos resultados mostrados na Tabela 4 .

Há que se considerar que a precipitação efetiva em relação ao total precipitado, de 6,6\%(Tabela 04), refere-se ao período de um ano e que a que se analisa no momento corres-
Tabela 4 - BMF: Balanço Hídrico Anual (2006-2007)

\begin{tabular}{l|c|c}
\multicolumn{1}{c|}{ Fase } & $\begin{array}{c}\text { Total } \\
(\mathrm{mm})\end{array}$ & $\begin{array}{c}\text { \% do Total } \\
\text { Precipitado }\end{array}$ \\
\hline Escoamento Superficial & 88 & 6,6 \\
\hline Infiltração & 243 & 18,1 \\
\hline Evapotranspiração & 1009 & 75,3 \\
\hline Precipitação média (2006-2007) & 1340 & 100 \\
\hline
\end{tabular}

Fonte: Extraída dos Resultados de Drumond (2008)

ponde a um evento de uma hora.

O valor da precipitação efetiva por evento apresenta, normalmente, grande variabilidade devida a fatores como intensidade, volume de chuva ou número de dias sem chuva antecedente. Se a intensidade do evento for alta, assim como seu volume, o percentual de precipitação efetiva sobre o volume de chuva, tende a ser bem mais alto que o que se obtém com um balanço anual. Por outro lado, caso o número de dias sem chuva seja elevado a precipitação efetiva poderá ser menor.

Para efeito comparativo, no caso em análise, a precipitação efetiva correspondente da BMF relativa ao evento 8 poderia ser estimada em 6,6\% de 49,2 mm, ou seja, 3,25 mm. Portanto, um valor bem próximo da precipitação efetiva do evento teórico $(3,34 \mathrm{~mm})$.

Logo, verifica-se uma compatibilidade na estreita relação entre os resultados práticos dos experimentos de Drumond e os do método de velocidade modificado aplicado à BMF.

Fica evidenciado que o dado de entrada de precipitação total, máxima de $24 \mathrm{~h}$ com período de retorno de 2 anos (80,04 $m m$ para a $\mathrm{BMF}$ ), ao entrar como variável no $m v T C_{M}$ passou a ser assimilado, implicitamente, como precipitação efetiva.

Através de análise da Tabela 02 , pode-se concluir que essa precipitação efetiva $(80,04 \mathrm{~mm})$ gera um escoamento superficial correspondente à faixa de elevados valores de $T$ (itens 1 a 5, Tabela 2) onde praticamente não ocorrem variações de $T C$ enquanto $T$ salta em décadas, como pode ser constatado também pela Figura 3 (Curva Ajustada TC x Q).

Convém lembrar, mais uma vez, que a estimativa do TC pelo $m v T C_{M}$ para a BMF utilizou simplificações para o cálculo do raio hidráulico.

Há que se considerar também as visitas de campo à bacia que apontaram alguns trechos dos cursos d'água a morfologia fluvial apresentando afloramentos de rocha. Essas elevações, atuando como como controles hidráulicos, produzem armazenamentos a montante, o que pode ter um efeito sobre o tempo de propagação da onda de cheia e, em consequência, sobre o $T C$. Uma vez que o $m v T C_{M}$ não considera o efeito de armazenamento, isso também pode justificar o porquê do valor calculado pelo o $m v T C_{M}$ encontrar-se no limite inferior do valor observado pela medição direta.

As variáveis $L$ (comprimento de fluxo) e $n$ (rugosidade de Manning) foram apontadas, em análise de sensibilidade por Fang, Pradhan e Malla (2007), como os mais importantes parâmetros para a estimativa pelo $m v$ TC.Os cuidados tomados para a geração e ajustes do MDT-HC já procuraram evitar eventuais problemas relativos à variável $L$.

Adicionalmente, procurou-se verificar implicações de 
uma majoração pontual induzida $(+20,33 \%)$, dentro da lógica do método de Cowan, na rugosidade de Manning para canais $n_{2}$ (onde houve medição direta do TC). Admitiu-se, para fins desse teste, uma alteração na variável $m_{5}$ - vegetação (Tabela 03), considerando-a muito alta $(0,075)$, o que resultou o valor de $n_{2}=$ 0,148 . Nessa hipótese, mantidas as demais condições, o valor de TCcel no ponto $T_{2}$ passaria de $0,94 \mathrm{~h}$ para $1,08 \mathrm{~h}(+14,89 \%)$ e o valor do TC de 1,85 h para 1,98 h (+7,03\%). Importante destacar que, nesse caso, onde se alterou apenas a rugosidade dos canais, não houve uma variação significativa do TC para a BMF. Mas, se esta majoração pontual ocorresse em bacia de maior dimensão, com predominância de fluxo de canais, esse aumento de valor na rugosidade poderia ser significativo no valor final do TC. Destaca-se, portanto que, apesar da aparente subjetividade, a escolha das variáveis de entrada precisa ser bastante criteriosa.

\section{CONCLUSÕES}

Este estudo pode contar, de fato, com o "valor verdade", ausente nas decisões sobre escolhas metodológicas para o TC, conforme referido por McCuen et al. (1984). A utilização dos resultados da pesquisa de medição direta, na Bacia do Mato Frio, constituiu importante diferencial que balizou as análises e proporcionou maior segurança na avaliação dos resultados obtidos. Esse fato evidenciou que o aperfeiçoamento das bases conceituais para estimativas de TC não pode persistir na dependência apenas de trabalhos isolados ou de publicações de pesquisas feitas de acordo com a realidade de outros países. É imprescindível que se promovam novos experimentos e que se garanta a continuidade de trabalhos como os de (DRUMOND, 2004, 2008).

$\mathrm{O} m v T C_{M}$ associado ao uso de geotecnologias possibilitou, principalmente, melhor conhecimento da bacia hidrográfica em estudo.

Diante da abundância de tantos conceitos, métodos e incertezas inerentes, o $m v T C_{M}$ mostrou-se eficiente e confiável para a estimativa do valor de TC que, ao ser utilizado como indicador para o planejamento de empreendimentos sustentáveis, deve ser igualado ou superado no pós-desenvolvimento.

$\mathrm{O}$ resultado da análise de consistência, associado às características fisiográficas da BMF e ao emprego da geotecnologia, ressaltou a necessidade de se alterar o conceito dominante sobre o TC. Brooks et al.(2013), a exemplo de muitos outros autores, utilizam a definição tradicional de TC como o tempo requerido para que toda a bacia contribua com o fluxo no $P C$. Entretanto, o geoprocessamento da BMF evidenciou que não é recomendável que um único ponto defina o comportamento da totalidade da bacia, independentemente de suas dimensões.

O maior valor de TCcel deve ser escolhido de forma a garantir que o TC estabeleça o momento em que uma porção significativa da bacia estiver contribuindo com o escoamento superficial no $P C$. Essa porção poderá atingir o valor de $100 \%$, dependendo das características fisiográficas da bacia ou da finalidade do uso do TC, cujo valor deve ser definido pelo projetista através da análise da distribuição espacial de tempos de concentração celular.
Conceitualmente consistente, o $m v T C_{M}$ pode ser aplicado em bacias urbanizadas ou não e permite, com a participação do projetista em cada fase intermediaria do processo, uma modelagem espacial específica para um caso em estudo.

A complexidade do fornecimento de muitos dados de entrada e operações de cálculo pode ser minimizada com o uso de geotecnologias. No caso do ArcGis, ferramenta de uso comum, todas as etapas podem ser automatizadas através do Python, permitindo que o processo de cálculo do TC se torne muito simples. Estabelecida a automatização do cálculo, um profissional, ainda que desconheça programação, conseguirá estimar o TC de forma semelhante à que realiza, por exemplo, a análise de declividades através de um modelo digital pelo ArcGis.

O resultado a ser obtido pelo $m v T C_{M}$ pode ser melhorado com a seleção criteriosa das variáveis de entrada. Nesse caso, tornam-se fundamentais a precisão das bases cartográficas e a realização de levantamentos de campo complementares.

Em relação às bases cartográficas, as perspectivas em futuro próximo mostram-se promissoras. Há hoje imagens de todo o planeta com resolução de $30 \mathrm{~m}$ acessíveis ao público (SRTM-Shuttle Radar Topography Mission/Topodata, ASTER-Shuttle Radar Topography Mission). Considerando-se a disponibilidade no mercado de imagens de alta qualidade, com resolução da ordem de $60 \mathrm{~cm}$, há a possibilidade de que, em horizonte não muito distante, modelos digitais com resoluções inferiores a 30 m estejam em domínio público.

O cálculo do TC, como proposto neste estudo, permite, de acordo com Maziero (2010), sua utilização criteriosa na forma de variável de entrada em softwares de modelagem hidrológica, podendo tornar desnecessária sua calibração como parâmetro hidrológico.

O uso da metodologia aqui empregada, ainda facilita o planejamento de experiências de campo para medição direta de TC. Os órgãos de planejamento, tomando como referência a metodologia de ajuste empregada por Sharifi e Hosseini (2011), também poderiam, por conveniência, utilizar o $m v T C_{M}$ para ajustar fórmulas empíricas comumente empregadas.

\section{REFERÊNCIAS}

AKAN, O. Time of concentration of overland flow. Journal of Irrigation na Drainage Engineerin, v. 112, p.283-292, 1986.

ALVAREZ, V. M. Determinación del tiempo de concentración con sistemas de información geográfica. Ingeniería del Agua, Córdoba, v. 3, n. 2, p.304-309, dez. 2006.

BAPTISTA, M. B.; COELHO, M. L. P. Fundamentos de Engenharia Hidráulica. 3. ed. Belo Horizonte: UFMG, 2010. 480p.

BEN-ZVI, A.; SHEVA, B. Bypassing determination of the time of concentration. Journal of Hydrologic Engineering. Reston, p. $1674-1683.7$ dez. 2013.

BILASCO, S. GIS methodology for the calculation of probable peak discharge time of concentration in small drainage basins: 
Case study. [Romanian Academy, Cluj Branch, Department of Geography]. Studia Ubb Geographia. Cluj-Napoca, p. 17-22. dez. 2011.

BROOKS, K. N.; FOLLIOTT, P. F.; MAGNER, J. A. .Hydrology and the management of watersheds, 4th ed., New Delhi: WileyBlackwell, 2013.

CHOW, V. T. Open channel hydraulics. New York: Mc GrawHill, 1959. 680 p.

CHOW V.T.; MAIDMENT, D.R.; MAYS, L.W. Applied Hydrology. New York: Mc Graw-Hill Book Company, 1988.

DAVIS, A. P.; McCUEN, R. H. Stormwater Management for Smart Growth. Maryland, 2005.

DER - Department Of Environmental Resource. Programs and Planning Division. Low-impact Development: An Integrated Design Approach. Prince George’s, Maryland. 1999. 150p.

DINIZ, M. G. M. Análise de Falhas em um Sistema de Drenagem Urbana Composto por Várias Bacias de Detenção. 2002. Dissertação (Mestrado em Saneamento, MeioAmbiente e Recursos Hídricos) - Escola de Engenharia, Universidade Federal de MinasGerais, Belo Horizonte, 2002.

DOD - Department of Defense. Unified Facilities Criteria (UFC): Low Impact Development. 6. Apr. 2010. UFC 3-210-10N.

DOOGE, J.C.I. Linear theory of hydrologic systems. U.S. Department of Agriculture, Agricultural Research Service, Technical Bulletin, 1408. 1973.

DRUMOND, M. M., A técnica de traçadores e o seu potencial para ampliar o conhecimento hidrológico sobre as bacias brasileiras: um estudo aplicado à bacia representativa de Juatuba - MG. 2004. 304f. Tese (Doutorado em Saneamento, MeioAmbiente e Recursos Hídricos) - Escola de Engenharia, Universidade Federal de MinasGerais, Belo Horizonte, 2004.

DRUMOND, M. M. (Org.). Relatório Final do Projeto de Pesquisa: Estudo da Formação de Escoamentos Utilizando a Técnica de Traçadores, na Bacia Representativa de Juatuba - Alto São Francisco. Belo Horizonte: CDTN, 2008. 128 p. (Ação PPA 6833 - Ação CNEN 0109 - Atividade 13 - Projeto 13.03 Hidrologia de Superfície). Projeto FINEP código 01.06.0109.00.

ENGMAN, E. T. Roughness coefficients for routing surfasse runnoff. Journal of Irrigation na Drainage Engineering, v. 112, n.1, p. 39-53,1986.

ESTEVES, R. L.; MENDIONDO, E. M. Análise comparativa entre equações e observações do tempo de concentração em uma bacia urbana de São Carlos. In: XV Simpósio Brasileiro de Recursos Hídricos, nov. 2003, Curitiba. Disponível em: <www. abrh.org.br>. Acesso em: 11 nov. 2007.
FALAGUASTA, L. N.; GENOVEZ, A. Maia Equações de Chuvas Intensas Generalizadas para os Estados de São Paulo e Paraná. Revista Brasileira de Recursos Hídricos, v. 8, n. 3, p. 169-176, jul. 2003.

FANG, X.; PRADHAN, P.; MALLA, R. Estimating time of concentration for Texas watersheds. In: FANG, X.; THOMPSON, D. B.; CLEVELAND, T. G.; PRADHAN, P.Variations of Time of Concentration Estimates Using NRCS Velocity Method. Journal of Irrigation and Drainage Engineering: ASCE, v.133, n.4, p. 314-322, jul. 2007.

FANG, X.; THOMPSON, D. B.; CLEVELAND, T. G.; PRADHAN, P.; MALLA, R. Time of Concentration Estimated Using Watershed Parameters Determined by Automated and Manual Methods. Journal of Irrigation and Drainage Engineering: ASCE, Newark, v. 134, n. 2, p.202-211, mar. 2008.

GIRARDI, E. P. Proposição de uma cartografia geográfica crítica e sua aplicação no desenvolvimento do atlas da questão agrária brasileira. 2008. Tese (Doutorado em Geografia) - Departamento de Geografia da Faculdade de Ciências e Tecnologia- UNESP, Presidente Prudente, 2008.

GREEN, J. I..; NELSON, E. J. Calculation of time of concentration for hydrologic design and analysis using geographic information system vector objects. Journal of Hydroinformatics, v.4, n.2, p. 75-81, 2002.

GRIMALDI, S.; NARDI, F.; DI BENEDETTO, F.I; STANBULLUOGLU; E.; BRAS, R. L. A physically-based method for removing pits in digital elevation models. Advances in Water Resources, v.30, n.10, p.2151-2158, 2007.

GRIMALDI, S.; PETROSELLI, A.; NARDI, F.; ALONSO, G. Flow time estimation with variable hillslope velocity in ungauged basins.Advances in Water Resources, v.33, n.10, p. 1216-1223, 2010.

GRIMALDI, S.; PETROSELLI, A.; TAURO, F.; PORFIRI, M. Time of concentration: a paradox in modern hydrology. Hydrological Sciences Journal, v.57, n.2, p. 217-228, 2012.

GUO, Y.; ADAMS, B. J. Hydrologic analysis of urban catchments with event-based probabilistic models. Water Resources Research, v. 34, n. 12, p. 3433-3443, 1998.

GUPTA, S. K. Modern Hydrology and Sustainable Water Development, Oxford, 2011.

HAWLEY, M. E.; BONDELID, T. R.; MCCUEN, R. H. A planning methodfor evaluating downstream effects of detention basins. Water Resources Bulletin, v. 17, n 5, p. 806-813, 1981.

IOWA. Stormwater Management Manual: 2C-8 Low-Impact Development (LID) Hydrology, 2008. 
Amanthea e Nascimento: Urbanização de baixo impacto (LID): Uso de geotecnologias para estimativa do tempo de concentração de bacia em cenário de pré-desenvolvimento.

KANG, Joo-Hyon; KAYHANIAN M.; STENSTROM, M. K.. Predicting the existence of stormwater first flush from thetime of concentration. Water Research, v. 42, p. $220-228,2008$.

KIBLER, D. F.; ARON, G. Evaluation of Tc methods for urban watersheds. In: Frontiers in Hydraulic Engineering (Proc. M.I.T. ASCE Symp.), p.553-559, 1993.

KOBIYAMA, M., et. al.. Estimativa morfométrica e hidrológica do tempo de concentração na bacia do campus da UFSC, Florianópolis-SC. In: I Simpósio de Recursos Hídricos do SulSudeste. Curitiba. 27-29 ago. 2006.

LIANG, J. MELCHING, C. S..Comparison of computed and experimentally assessed times of concentration for a $\mathrm{v}$-shaped laboratory watershed. Journal of Hydrologic Engineering, v.17, p. 1389-1396, 2012.[DOI: 10.1061/(ASCE)HE.1943-5584.0000609]

LOUKAS, A.; QUICK, M. C .Physically-based estimation of lag time forforested mountainous watersheds. Hydrological Sciences: Journal- des Sciences Hydrologiques, v.41, n.1, feb., p.1-19, 1996.

MAIDMENT, D. R. Handbook of Hydrology. New York: McGraw-Hill, 1993.

MATA-LIMA, H.; VARGAS, H.; CARVALHO, J.; GONÇALVES, M.; CAETANO, H.; MARQUES, A.; RAMINHOS, C. Comportamento hidrológico de bacias hidrográficas: integração de métodos e aplicação a um estudo de caso. Revista Escola de Minas, Ouro Preto, v. 60, n. 3, p. 525-536, jul. 2007.

MAZIERO, E. Histograma tempo/área geoprocessado: Modelo chuva-vazão concentrado. 2010. 116 f. Dissertação (Mestrado - Curso de Engenharia Civil) - Departamento de Centro de Tecnologia, Universidade Federal de Santa Maria, Santa Maria, 2010.

McCUEN, R. H., WONG, S. L.; RAWLS, W. J. Estimating the time of concentration of urban watershed. Frontiers of Hydraulic Engineering, American Society of Civil Engineers, p.547-552, 1983.

McCUEN, R. H.; WONG, S. L.; RAWLS, W. J. Estimating urban time of concentration. Journal of Hydrologic Engineering, v.110, n.7, p.887-904, 1984

McCUEN, R. H.; SPIESS, J. M.. Assessment of kinematic wavetime of concentration. American Society of Civil Engineers. Journal of Hydraulic Engineering, v.121, n.3, p.256-266, 1995.

McCUEN, R.H. Hydrologic analysis and design. 2nd ed. New Jersey: Prentice Hall, 1998.

McCUEN, R.H. Uncertainty analyses of watershed time parameters. Journal of Hydrologic Engineering, v.14, n.5, p. 490-498. 2009.
NYS - New York State. Stormwater Management Design Manual. 2010. 642p.

PAPADAKIS, C. N.; KAZAN, M. N. Time of Concentration in Small Rural Watersheds. Proceedings of the 1987 ASCE Engineering Hydrology Symposium, Williamsburg, p.633-638, 1987.

PILGRIM D.H. Travel times and nonlinearity of flood runoff from tracer measurements on a small watershed. Water Resources Research, v. 12, p. 487-496, 1976.

PIRES, J. M.; NASCIMENTO, M. C.; SANTANA, R. M.; RIBEIRO C. A. A. S. Análise da exatidão de diferentes métodos de interpolação para geração de modelos digitais de elevação e obtenção de características morfométricas em bacias hidrográficas. Revista Brasileira de Recursos Hídricos, Porto Alegre, v. 10, n. 2, p. 39-47, abr. 2005.

RAMOS, J. A. S. (org). Análise espacial de bacias hidrográficas. LABGIS - Universidade do Estado do Rio de Janeiro (UERJ). Rio de Janeiro, 2013.

SHARIFI, S.; HOSSEINI, S.M. Methodology for identifying the best equations for estimating the time of concentration of watersheds in a particular region. Journal of Irrigation and Drainage Engineering: ASCE, v.137, n.11, p.712-719, 2011. [DOI: 10.1061/ (ASCE)IR.1943-4774.0000373].

SILVA, B. C.; TUCCI, C. E. M.; COLLISCHONN, W. Previsão de vazão com modelos hidroclimáticos. Revista Brasileira de Recursos Hídricos, Porto Alegre, v. 11, n. 3, p. 15-29, jul. 2006.

SILVEIRA, A. L. L. Desempenho de Fórmulas de Tempo de Concentração em bacias Urbanas e Rurais. Revista Brasileira de Recursos Hídricos, Porto Alegre, v. 10, n. 1, p. 5-23, jan. 2005.

SINGH, V. P. Hydrologic Systems, I, Rainfall-Runoff Modeling, Prentice-Hall, Englewood Cliffs, N.J., v.1, 1988.

SINGH, V. P.; XU, Y. J. Coastal Hydrology and Processes. Colorado: Water Resources Publications LLC, 2006. p. 465-479.

SOARES, R. C. V. Caracterização do fluxo subterrâneo das águas na porção sudoeste da bacia representativa de Juatuba. 2010. 162 f. Dissertação (Mestrado em Saneamento, Meio Ambiente e Recursos Hídricos) - Programa de Pós-graduação em Saneamento, Meio Ambiente e Recursos Hídricos da Universidade Federal de Minas Gerais, Belo Horizonte, 2010 [Base de Dados].

TODINI, E.; MARTINA , M. L.V. Idrologia e rischio idrologico: I modeli idrologici. Università di Bologna. Dipartimento di Scienze della Terra e Geologico-Ambientali. 2008. Disponível em: <http://www.hydro.unibo.it/teaching/IRI/slides/07_ ModelliIdrologici.pdf $>$. Acesso em 08 out. 2012.

TUCCI, C. E. M. Hidrologia: ciência e aplicação. 2. ed. Porto 
Alegre: Ed. da UFRGS, 2001. 943 p.

UPEGUI, J. J.; GUTIÉRREZ, B. A.. Estimación del tiempo de concentración y tiempo de rezago en la cuenca experimental urbana de la quebrada San Luis, Manizales. Dyna - Revista de la Facultad de Minas, Medellín, v.78, n.165, p. 58-71, 2011.

USDA - United States Department of Agriculture. Urban hydrology for small watersheds. Technical Release 55 (TR-55). jun. 1986

VERSACE, P. Modelli di trasformazione afflussi-deflussi. Università della Calabria. Facolta' di Ingegneria.Corso di Laurea in Ingegneria per l'Ambiente e il Territorio. 2004.

WILKEN, P. S. Engenharia de Drenagem Superficial. São Paulo: CETESB - Companhia de Tecnologia de Saneamento Ambiental, 1978. 477p.

WONG, T. S. W. Assessment of Time of Concentration Formulas for Overland Flow. Journal of Irrigation and Drainage Engineering: ASCE, Newark, v.131, n.4, p.383-387, 2005.

WONG, T. S. W. Evolution of kinematic wave time of concentration formulas for overland flow. Journal of Irrigation and Drainage Engineering: ASCE, Newark, v.14, n.7, p.739-744, 2009. 